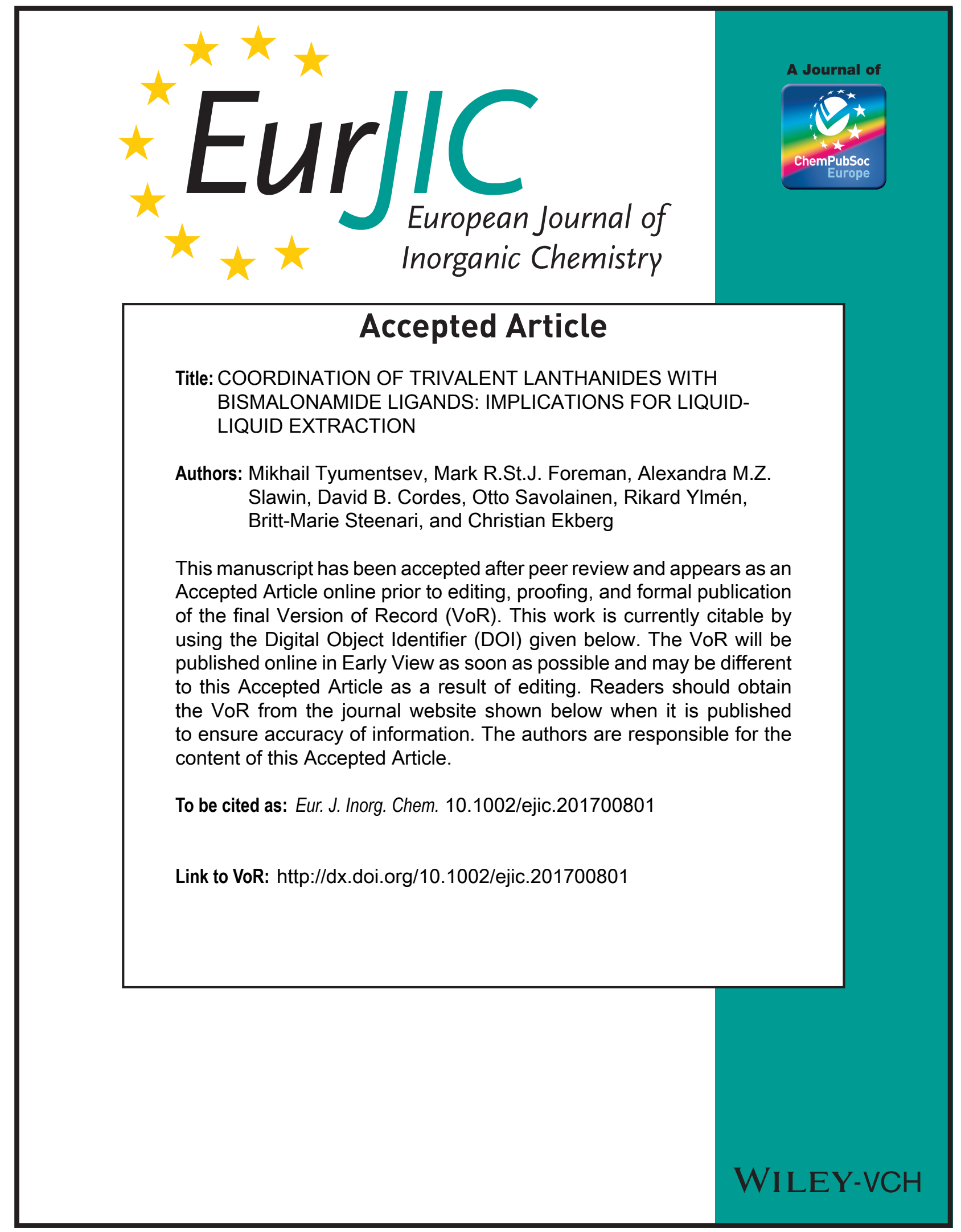




\section{COORDINATION OF TRIVALENT LANTHANIDES WITH BISMALONAMIDE LIGANDS: IMPLICATIONS FOR LIQUID-LIQUID EXTRACTION}

Mikhail S. Tyumentsev ${ }^{[a] *}$, Mark R.St.J. Foreman ${ }^{[a]}$, Alexandra M.Z. Slawin ${ }^{[b]}$, David B. Cordes ${ }^{[b]}$, Otto Savolainen ${ }^{[c]}$, Rikard Ylmén ${ }^{[a]}$, Britt-Marie Steenari ${ }^{[a]}$, Christian Ekberg ${ }^{\text {[a] }}$

[a] Nuclear Chemistry and Industrial Materials Recycling

Department of Chemistry and Chemical Engineering Chalmers University of Technology, SE-412 96, Gothenburg, Sweden

${ }^{[b]}$ School of Chemistry, University of St. Andrews Purdie Building, North Haugh, St. Andrews, Fife, Scotland, KY16 9ST, Great Britain

${ }^{[c]}$ Chalmers Mass Spectrometry Infrastructure (CMSI) Department of Biology and Biological Engineering Chalmers University of Technology, SE-412 96, Gothenburg, Sweden

${ }^{*}$ Corresponding author. Tel.: +46 (0) 317722842

E-mail address: miktyu@ chalmers.se https://www.chalmers.se/en/staff/Pages/miktyu.aspx

Key words:

Lanthanides; Bismalonamides; Single-Crystal X-Ray Diffraction; Electrospray Ionization Mass Spectrometry; Liquid-Liquid Extraction 


\section{Abstract}

The complexation of the bismalonamide ligand 2,2'-(1,2phenylenebis(methylene)) bis( $N, N, N^{\prime}, N^{\prime}$-tetraethylmalonamide) (L), bearing two $C$-alkylated $N, N, N^{\prime}, N^{\prime}$-tetraethylmalonamide groups onto ortho-xylylene $\left(\mathrm{C}_{6} \mathrm{H}_{4}\left(\mathrm{CH}_{2}\right)_{2}\right)$ platform, with trivalent lanthanides was investigated both in solid- and solution states. The crystal structures $\left[\mathrm{Nd}_{2}\left(\mathrm{NO}_{3}\right)_{6} \mathrm{~L}_{2}\right] \cdot\left(\mathrm{CH}_{3} \mathrm{CN}\right)_{3}(\mathbf{2}),\left[\mathrm{Nd}_{2}\left(\mathrm{NO}_{3}\right)_{4} \mathrm{~L}_{2}\right] \cdot\left[\mathrm{Nd}\left(\mathrm{NO}_{3}\right)_{5}\right] \cdot\left(\mathrm{CH}_{3} \mathrm{CN}\right)_{1.5}(\mathbf{3}), \mathrm{Ce}\left(\mathrm{NO}_{3}\right)_{3} \mathrm{~L}_{2}(\mathbf{4})$ and $\left[\mathrm{NdL}_{2}\right] \cdot\left(\mathrm{ClO}_{4}\right)_{3} \cdot \mathrm{C}_{2} \mathrm{H}_{5} \mathrm{OH}(5)$ were analyzed by single-crystal X-ray diffraction. The orthobismalonamide (L) is tetradentate in the structures $\mathbf{2}, \mathbf{3}$ and $\mathbf{5}$ and bidentate in $\mathbf{4}$ only. It was found that the structures $\mathbf{2}$ and $\mathbf{3}$ are composed of dimeric species. According to electrospray ionization - mass spectrometry the dimers are prevailing in acetonitrile solutions. The polydentate coordination of the ortho-bismalonamide (L) with trivalent lanthanides suggests that an entropy effect favors liquid-liquid extraction of the metal ions with this type of ligands. 


\section{Introduction}

Advanced hydrometallurgical recycling of electric and electronic waste streams, that include neodymium-iron-boron $(\mathrm{NdFeB})$ and samarium-cobalt $(\mathrm{SmCo})$ permanent magnets, fluorescent lamp phosphors rich in rare earths (Y, Eu, Tb), nickel - metal ( $\mathrm{La}, \mathrm{Ce}$ ) - hydride car batteries and other end-of-life items [1,2], as well as spent nuclear fuel [3] demands efficient and environmentally friendly liquid-liquid extraction ligands for recovery of lanthanide (Ln) metals. The common requirement for such new ligands is their complete incinerability. This requirement is motivated by research on nuclear fuel recycling, showing that the incineration of a redundant liquid-liquid extraction ligand reduces the secondary waste generation [3, 4].

We believe that novel malonamide-based extractants can contribute to the development of advanced hydrometallurgical technologies for recycling of lanthanides. Malonamides are known to extract trivalent lanthanide ions from aqueous solutions [5-8]. They comply with the criterion of being completely incinerable ligands. Malonamides are stable at high concentrations of mineral acids and do not form undesirable by-products upon radiolysis [9]. But in spite of that they have noticeable disadvantage of fairly low distribution ratios of trivalent lanthanides in comparison to some other liquid-liquid extraction ligands, such as $N, N, N^{\prime}, N^{\prime}-$ tetraoctyldiglycolamide (TODGA) [10]. The possible solution to this problem is to increase the denticity, i.e. the number of coordination sites, of the bidentate malonamides. Since trivalent lanthanides have high coordination numbers (e.g. nine in aqueous solutions for most $\mathrm{Ln}$ (III) ions [11]) it is argued that the application of polydentate liquid-liquid extraction ligands, often referred to as multicoordinate ligands [12], might result in higher distribution ratios of these metal ions due to the entropic effect $[12,13]$.

The 'polydentate' approach to the design of new malonamide-based extractants for trivalent $\mathrm{f}$ block elements was employed by several research groups, who synthesized a number of bisand trismalonamide derivatives by linking two or three bidentate malonamides with a carrier molecule (a platform) [13-15]. In these extractants the number of malonamide ligating groups onto platforms (i.e. two in bis- and three in trismalonamides, respectively) was selected with an intention to replicate the 1:2 or 1:3 metal-to-ligand ratios of known nitrato complexes of trivalent lanthanides with conventional (bidentate) malonamide ligands, carrying two coordinating carbonyl oxygen atoms [13-15]. Obviously there was a hope that all malonamide fragments of a molecule of these polydentate extractants would coordinate to a central lanthanide(III) ion. In other words it was anticipated that bis- and trismalonamides would extract trivalent lanthanides as tetra- and hexadentate ligands, respectively. Otherwise little 
entropy-induced gain in a free Gibbs' energy of a metal extraction can be expected for these ligands, and consequently the increase in the distribution ratios of lanthanides(III) likely would not happen.

While D. Janczewski et al. reported that the trismalonamides show low distribution ratios of trivalent europium similar to those for conventional bidentate malonamides [14], M.T. Murillo et al. demonstrated that the bismalonamides can outperform bidentate malonamides in the extraction of $\mathrm{Eu}(\mathrm{III})$ [13]. However it was noticed for the bismalonamide ligands that the structure of a platform as well as the mode of attachment of a malonamide units to a platform (i.e. by $N$ - or $C$-alkylation) affect strongly the distribution ratio of $\mathrm{Eu}(\mathrm{III})$, so that only some bismalonamides displayed higher distribution ratios than the reference bidentate malonamides [13].

The analysis of the coordination of the polydentate malonamides with trivalent lanthanides could explain the reasons for their different liquid-liquid extraction performance. So far the studies of the lanthanide(III) complexes with bis- and trismalonamides were limited solely to the liquid-liquid extraction experiments, namely the analysis of the stoichiometry of extracted species by the method of slopes [13-15]. Unfortunately this method has serious limitations: when correctly applied it can only tell one the empirical ratio between a metal and a ligand in species extracted into an organic phase, not answering the important question of the spatial arrangement of ligands around the metal ion. Thus, despite knowing the metal-to-ligand ratios in the extracted species from the slope analysis (it was ranging from 1:2 to 1:2.7 for the examined bismalonamides), M.T. Murillo et al. could not determine the coordination environment of $\mathrm{Eu}(\mathrm{III})$ in these complexes, i.e. it was unclear whether the studied bismalonamides were acting as mono-, bi- or polydentate ligands [13]. As a result the differences in the performance of the bismalonamides in liquid-liquid extraction of $\mathrm{Eu}(\mathrm{III})$ remained unexplained.

The absence of any coordination studies of the polydentate malonamide complexes with trivalent lanthanides became the bottleneck for the development of this group of liquid-liquid extraction ligands. The work described in this paper was aiming at helping to fill in this gap of knowledge. Recently we have reported new bismalonamide ligand - 2,2'-(1,2phenylenebis(methylene)) bis( $N, N, N^{\prime}, N$ '-tetrabutylmalonamide) - bearing two $C$-alkylated malonamide units onto an ortho-xylylene platform, which demonstrated higher distribution ratios of $\operatorname{Ln}(\mathrm{III})$ than the reference bidentate malonamide [16]. We extend this research with a focus on the coordination studies of the bismalonamide ligands with trivalent lanthanides. Four new crystal complexes of the bismalonamide with trivalent lanthanides were prepared and 
analyzed with single-crystal X-ray diffraction (XRD). Thus information regarding the coordination environment of lanthanide(III) ions in their complexes with the bismalonamide ligand was collected. In spite of the fact that single-crystal XRD is known as one of the best methods for structural determination, its results are valid for solid state complexes and should not be extrapolated directly to the related complexes in solutions. Keeping this in mind we complemented our single-crystal XRD research with the solution-state studies of the bismalonamide-lanthanide(III) complexes using electrospray ionization - mass spectrometry (ESI-MS). 


\section{Results and Discussion}

\section{Crystal structures.}

The bismalonamide 2,2'-(1,2-phenylenebis(methylene))bis( $N, N, N^{\prime}, N^{\prime}$-tetrabutylmalonamide) (1a) was found to be particularly efficient at extracting trivalent lanthanide ions from nitric acid solutions [16]. It was suggested that this ligand could coordinate to a metal ion with four carbonyl oxygen atoms, as its ortho-xylylene platform holds two malonamide groups close together [16]. This coordination mode promotes favorable entropy changes of the reaction and therefore might explain increased distribution ratios of lanthanide(III) ions with bismalonamide $\mathbf{1 a}$ in the process of liquid-liquid extraction.

Ligands such as 1a, being used for liquid-liquid extraction of metal ions, usually contain long alkyl (chained or branched) groups in their structures to enhance the solubility of extracted complexes in organic solvents. As a rule such ligands are not suitable for collecting crystallography data because long alkyl groups decrease the crystallinity of metal complexes. Homologous ligands with shorter alkyl groups are used instead for crystallography research [17], since it is argued that they form complexes with an equal coordination environment of a metal. For instance, different length of alkyl groups in $\mathrm{N}$-tetrasubstituted methylmalonamide [18], ethylmalonamide [19] and butylmalonamide [20] does not change the coordination environment of a lanthanum(III) central ion in the respective nitrato crystal complexes.

In our work 2,2'-(1,2-phenylenebis(methylene)) bis( $N, N, N^{\prime}, N^{\prime}$-tetraethylmalonamide), which is the octaethyl homologue of bismalonamide 1a, was prepared. Named as bismalonamide $\mathbf{1 b}$ and denoted as $\mathrm{L}$ in the structural formulae, this ligand was used to grow crystal complexes with trivalent lanthanide ions. Bismalonamide $\mathbf{1 b}$ was reacted with every member of the lanthanide series, excluding radioactive promethium, in nitrate media in acetonitrile. However single crystals, suitable for a structure determination, were obtained only for the neodymium and cerium compounds. No attempt was made to prepare perchlorate single crystal complexes of bismalonamide $\mathbf{1 b}$ with the whole lanthanide series, only the neodymium(III) complex was prepared.

The coordination of the lanthanides in the obtained structures, described below, was investigated with single-crystal XRD.

$\left[\mathrm{Nd}_{2}\left(\mathrm{NO}_{3}\right)_{6} \mathrm{~L}_{2}\right] \cdot\left(\mathrm{CH}_{3} \mathrm{CN}\right)_{3}$ (2). The compound $\mathbf{2}$ is composed of the dimeric species $\mathrm{Nd}_{2}\left(\mathrm{NO}_{3}\right)_{6} \mathrm{~L}_{2}$ and three molecules of acetonitrile (the solvent), trapped in cavities in the crystal. There are two crystallographically equivalent neodymium atoms in the dimer $\mathrm{Nd}_{2}\left(\mathrm{NO}_{3}\right)_{6} \mathrm{~L}_{2}$. 
Each of these is 10-coordinate and bonded to three bidentate nitrate anions and two bidentate $N, N, N^{\prime}, N^{\prime}$-tetraethylmalonamide units from two different molecules of the ligand L (Figure 1).

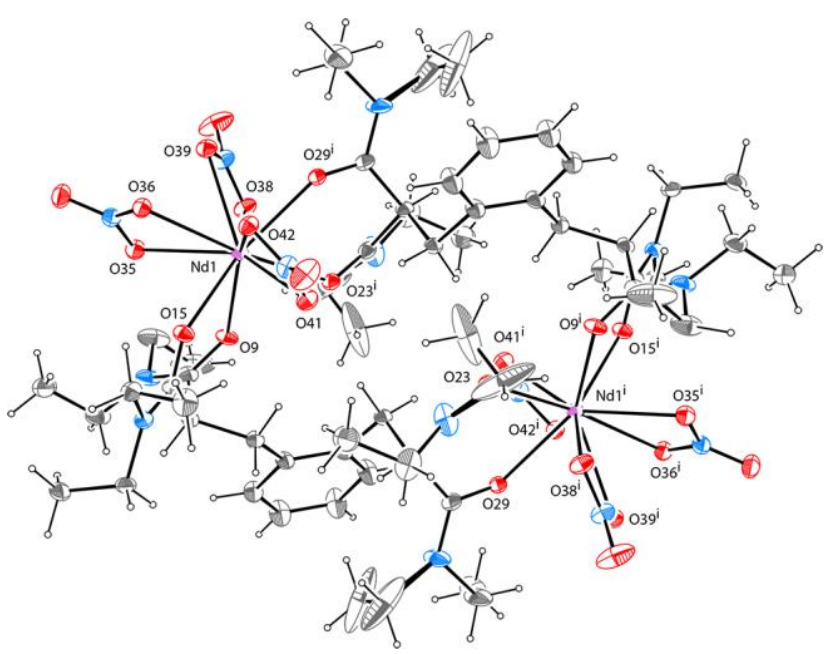

$\mathbf{a}$

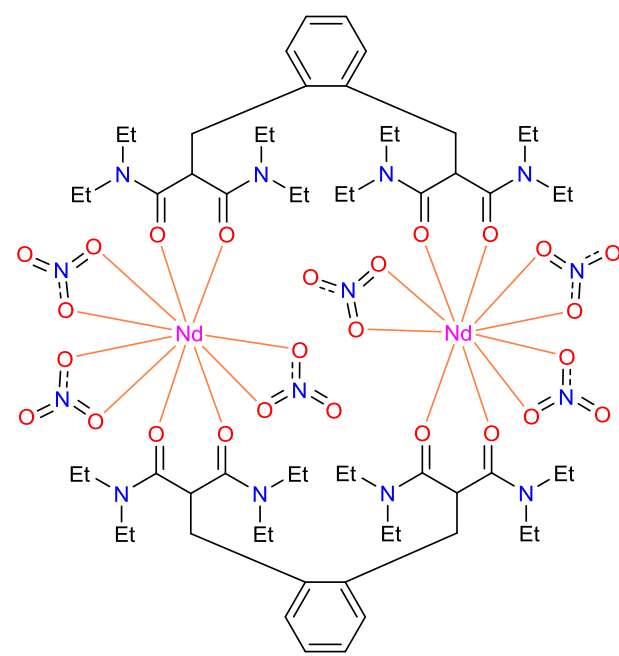

b

Figure 1. The structure of $\left[\mathrm{Nd}_{2}\left(\mathrm{NO}_{3}\right)_{6} \mathrm{~L}_{2}\right] \cdot\left(\mathrm{CH}_{3} \mathrm{CN}\right)_{3}(2)$ :

a - ORTEP drawing (30\% probability ellipsoids); carbon - gray, oxygen - red, nitrogen blue, hydrogen - white; molecules of solvent $\left(\mathrm{CH}_{3} \mathrm{CN}\right)$ have been omitted for clarity; $\mathrm{b}$ - chemical diagram of 2 .

This coordination number, as well as the location of the nitrate anions in the inner coordination sphere of the metal, is typical for the nitrato complexes of neodymium(III) with other malonamides [21-23]. The coordination polyhedron of $\mathrm{Nd}$ is a distorted bicapped square antiprism (Figure 2).

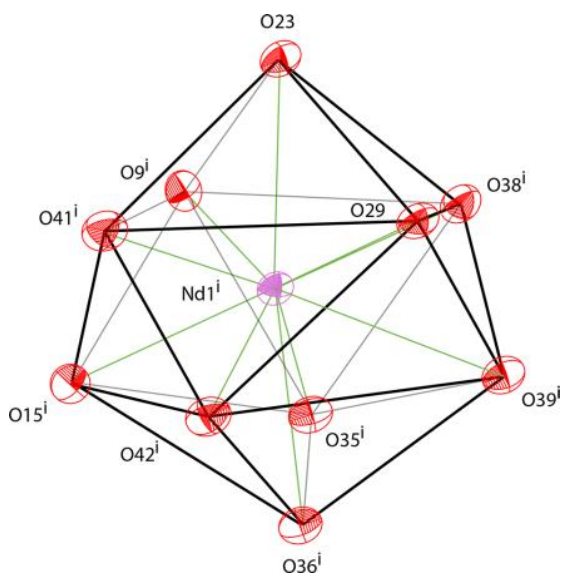

a

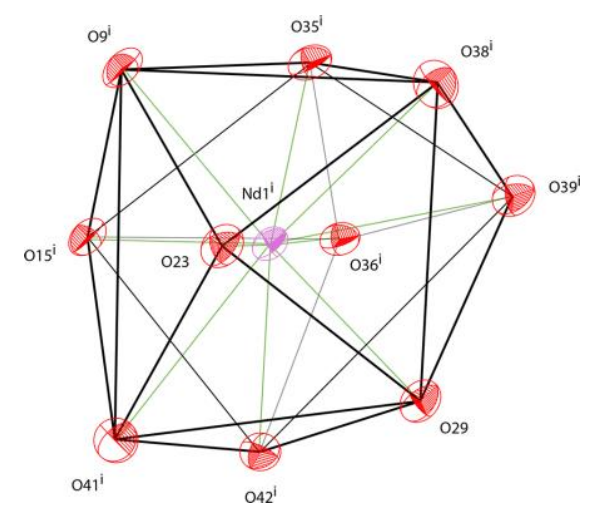

b

Figure 2. The coordination polyhedron of the $\mathrm{Nd}^{3+}$ ion in $\mathbf{2}$ (bicapped square antiprism): $\mathrm{a}$ - side view; $\mathrm{b}$ - top view. 
The bond distances between neodymium(III) ion and its coordination environment (i.e. nitrates and malonamide moieties) in the compound $\mathbf{2}$ are listed in Table S1. These are similar to the corresponding distances in the nitrato complexes of $\mathrm{Nd}(\mathrm{III})$ with conventional bidentate malonamides reported in the literature [21-23].

The unique feature of the compound $\mathbf{2}$, which clearly distinguishes it from all known crystalline nitrato complexes of lanthanide(III) ions with malonamides, is the binuclear coordination of the ligand with neodymium(III) (the distance between two $\mathrm{Nd}$ atoms in the dimeric complex is $8.467 \AA$ ). Moreover, the binuclear species $\mathrm{Nd}_{2}\left(\mathrm{NO}_{3}\right)_{6} \mathrm{~L}_{2}$ in 2 is a macroheterocycle rather than a bridge-type structure such as the binuclear complexes of lanthanide(III) nitrates with succinamides [24]. The metal-to-ligand stoichiometry in 2 is 2:2 (or 1:1 when the empirical ratio of Nd-to-L is considered).

$\left[\mathrm{Nd}_{2}\left(\mathrm{NO}_{3}\right)_{4} \mathrm{~L}_{2}\right] \cdot\left[\mathbf{N d}\left(\mathrm{NO}_{3}\right)_{5}\right] \cdot\left(\mathrm{CH}_{3} \mathbf{C N}\right)_{1.5} \quad$ (3). The structure 3 consists of two crystallographically independent halves of the cationic complex $\left[\mathrm{Nd}_{2}\left(\mathrm{NO}_{3}\right)_{4} \mathrm{~L}_{2}\right]^{2+}$, the anionic complex $\left[\mathrm{Nd}\left(\mathrm{NO}_{3}\right)_{5}\right]^{2-}$ and molecules of acetonitrile (the solvent), trapped in cavities in the crystal. The cations are the centrosymmetric dimeric species $\mathrm{Nd}_{2}\left(\mathrm{NO}_{3}\right)_{4} \mathrm{~L}_{2}$ that contain two crystallographically equivalent neodymium(III) atoms and two bismalonamide $\mathbf{1 b}$ ligands (Figure 3). Each of the Nd atoms in the complex cation is 9-coordinate and bonded with two bidentate $N, N, N^{\prime}, N^{\prime}$-tetraethylmalonamide units from two different molecules of the ligand, one bidentate nitrate, one monodentate and one bidentate bridging nitrates. These two bridging nitrates connect two neodymium atoms in the cation $\left[\mathrm{Nd}_{2}\left(\mathrm{NO}_{3}\right)_{4} \mathrm{~L}_{2}\right]^{2+}$ through two $\mathrm{Nd}$ $\mathrm{O}$ (nitrate)-Nd bridges. Such bridges are rare for the nitrato complexes of lanthanides [25]. 
$\mathbf{a}$

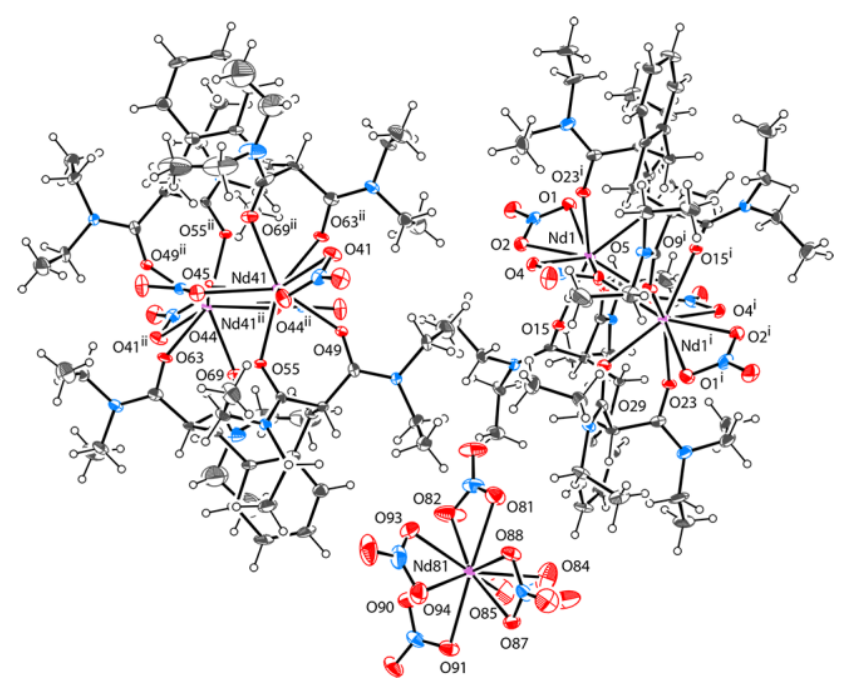

b
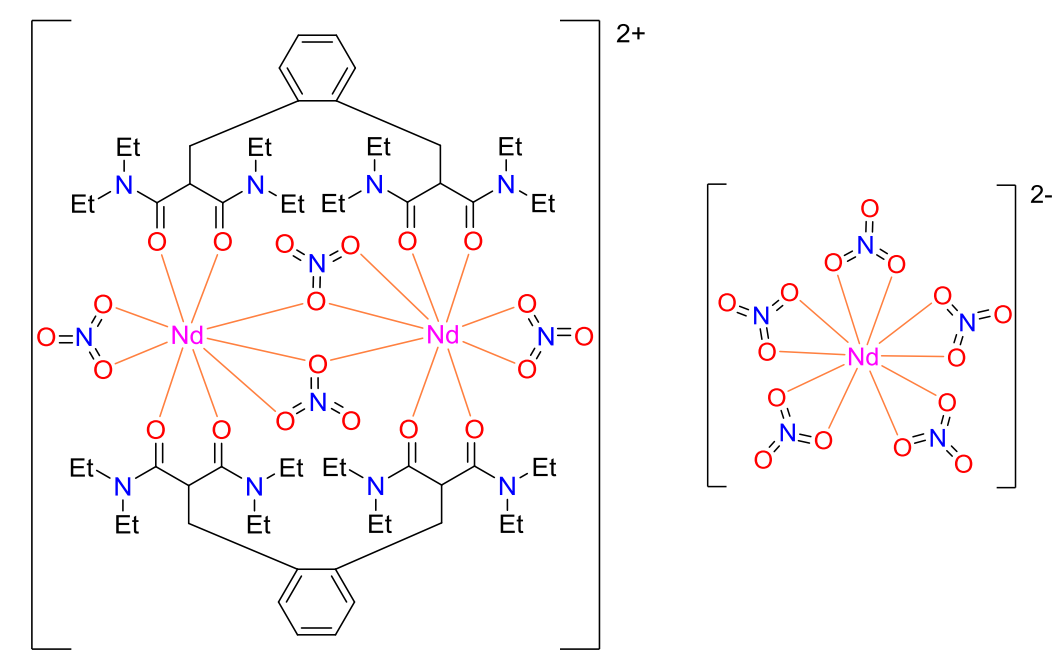

Figure 3. The structure of $\left[\mathrm{Nd}_{2}\left(\mathrm{NO}_{3}\right)_{4} \mathrm{~L}_{2}\right] \cdot\left[\mathrm{Nd}\left(\mathrm{NO}_{3}\right)_{5}\right] \cdot\left(\mathrm{CH}_{3} \mathrm{CN}\right)_{1.5}(\mathbf{3})$ :

a - ORTEP drawing (30\% probability ellipsoids); carbon - gray, oxygen - red, hydrogen white; molecules of solvent $\left(\mathrm{CH}_{3} \mathrm{CN}\right)$ have been omitted for clarity;

$\mathrm{b}-$ chemical diagram of the cation $\left[\mathrm{Nd}_{2}\left(\mathrm{NO}_{3}\right)_{4} \mathrm{~L}_{2}\right]^{2+}$ and anion $\left[\mathrm{Nd}\left(\mathrm{NO}_{3}\right)_{5}\right]^{2-}$ of $\mathbf{3}$.

The coordination polyhedra of the neodymium(III) ions in the complex cation can be described as distorted tricapped trigonal prisms (Figure 4), typical for trivalent lanthanide ions in aqueous solutions [11]. The complex anion $\left[\mathrm{Nd}\left(\mathrm{NO}_{3}\right)_{5}\right]^{2-}$ consists of a 10-coordinate central neodymium ion bonded with five bidentate nitrates. Its coordination polyhedron is a distorted bicapped square antiprism.

The bond distances of neodymium(III) ions in the cation $\left[\mathrm{Nd}_{2}\left(\mathrm{NO}_{3}\right)_{4} \mathrm{~L}_{2}\right]^{2+}$ (mean value $2.483(8)$ $\AA$ ) and anion $\left[\mathrm{Nd}\left(\mathrm{NO}_{3}\right)_{5}\right]^{2-}$ (mean value $2.51(1) \AA$ ) in the structure $\mathbf{3}$ are different due to the difference in the coordination environment of these metal ions (Table S1). The distances between two $\mathrm{Nd}$ atoms in the crystallographically independent halves of the cationic complex 
$\left[\mathrm{Nd}_{2}\left(\mathrm{NO}_{3}\right)_{4} \mathrm{~L}_{2}\right]^{2+}$ are equal to $4.388 \AA$ and $4.394 \AA$, being approximately twice shorter than that in the structure 2.

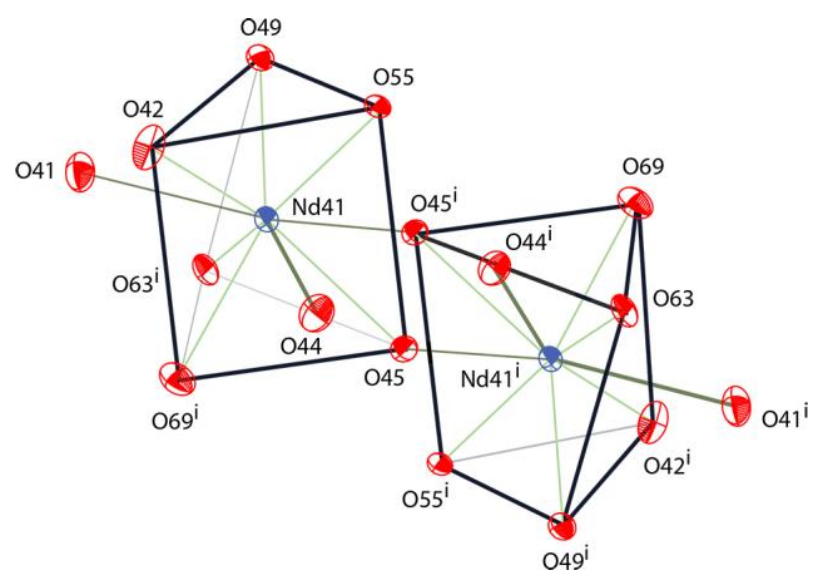

a

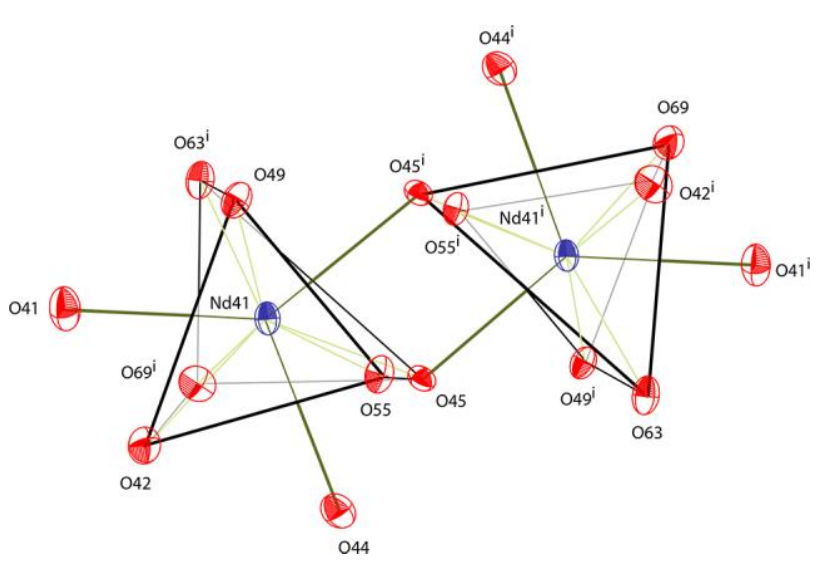

b

Figure 4. The coordination polyhedra of $\mathrm{Nd}^{3+}$ ions in the cation $\left[\mathrm{Nd}_{2}\left(\mathrm{NO}_{3}\right)_{4} \mathrm{~L}_{2}\right]^{2+}$ of $\mathbf{3}$ (tricapped trigonal prisms bridged by $\mathrm{O} 45$ and $\mathrm{O} 45^{\mathrm{i}}$ oxygen atoms): $\mathrm{a}$ - side view; $\mathrm{b}$ - top view.

The metal-to-ligand stoichiometry in $\mathbf{3}$ is $3: 2$, however it is equal to $2: 2$ in the cation $\left[\mathrm{Nd}_{2}\left(\mathrm{NO}_{3}\right)_{4} \mathrm{~L}_{2}\right]^{2+}$, like in the structure 2 .

$\mathrm{Ce}\left(\mathrm{NO}_{3}\right)_{3} \cdot \mathbf{L}_{2}$ (4). The compound 4 is composed of a cerium(III) cation, two bismalonamide $\mathbf{1 b}$ ligands and three nitrate anions. The cerium(III) ion is 10 -coordinate. It is surrounded by two chelating bidentate malonamide units from two bismalonamide ligands and three bidentate nitrates (Figure 5). The nitrates, as in the structures $\mathbf{2}$ and $\mathbf{3}$, are located in the inner coordination sphere of cerium. One nitrate is disordered over two positions. The coordination polyhedron of $\mathrm{Ce}$ is a distorted bicapped square antiprism. 


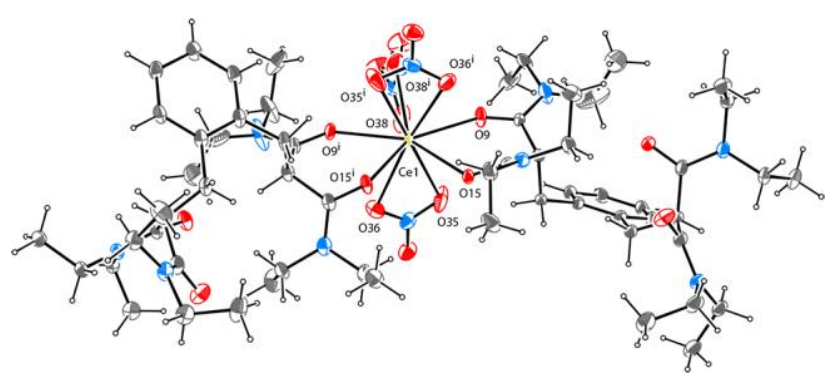

$\mathbf{a}$

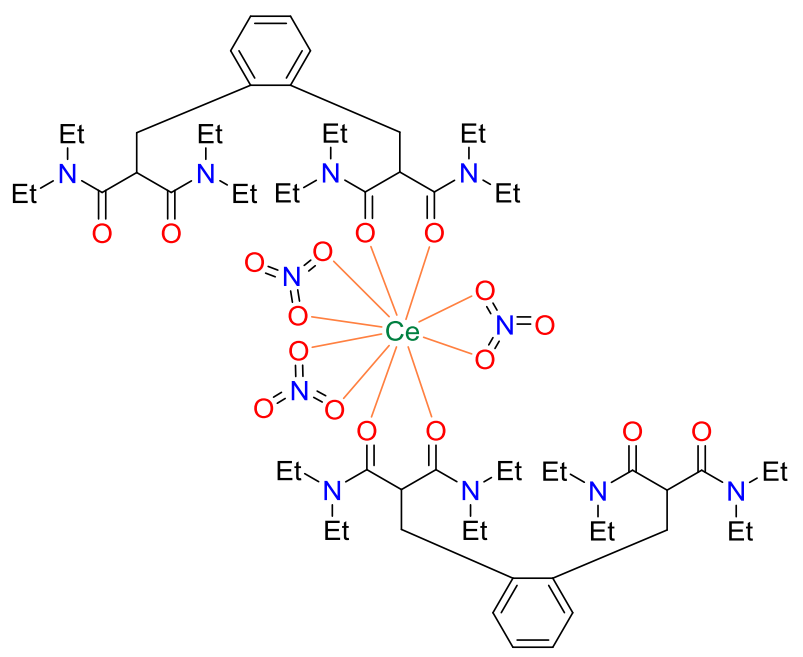

b

Figure 5 - The structure of $\mathrm{Ce}\left(\mathrm{NO}_{3}\right)_{3} \cdot \mathrm{L}_{2}(\mathbf{4})$ :

a - ORTEP drawing (30\% probability ellipsoids); carbon - gray, oxygen - red, nitrogen blue, hydrogen - white; $b$ - chemical diagram of 4 .

There is a $C 2$ rotational symmetry in the complex 4 . The $C 2$ axis passes through the cerium atom and the average of the two locations of the disordered nitrate's nitrogen atom (Figure 5). The bond distances of the Ce(III) coordination environment are reported in Table S1. The mean value of the $\mathrm{Ce}^{3+}-\mathrm{O}$ bond distances in 4 (2.57(1) $\AA$ ) is larger than that in the neodymium(III) complex 2 (2.54(1) $\AA$ ), which can be reconciled by the difference in the ionic radii of the two ions [26]. The compound $\mathbf{4}$ has a metal-to-ligand stoichiometry of 1:2.

Despite the quality of the crystallographic data for the compound $\mathbf{4}$ is lower than desired we regard this species as an important one. The structure 4 illustrates that it is possible to open the macrocycle in $\mathbf{2}$ by bonding a single metal atom only to half of the amide oxygen atoms present in a molecule of the bismalonamide.

[NdL2] $\cdot\left(\mathrm{ClO}_{4}\right)_{3} \cdot \mathrm{C}_{2} \mathrm{H}_{5} \mathrm{OH}(5)$. The compound $\mathbf{5}$ is the complex of neodymium(III) perchlorate with bismalonamide $\mathbf{1 b}$. It consists of one large complex cation $\left[\mathrm{NdL}_{2}\right]^{3+}$, three perchlorate anions $\mathrm{ClO}_{4}^{-}$and one molecule of ethanol (the solvent) trapped in cavities in the crystal. The $\mathrm{Nd}(\mathrm{III})$ ion has an 8-coordinate environment. It is bonded with four bidentate $N, N, N^{\prime}, N^{\prime}$ tetraethylmalonamide units from two different molecules of the ligand (Figure 6). The coordination polyhedron of $\mathrm{Nd}$ is a distorted square antiprism (Figure 7). In contrast to nitrates in the compounds $\mathbf{2 - 4}$, the perchlorates in $\mathbf{5}$ are located outside the inner coordination sphere of neodymium(III), i.e. they are non-coordinating. The metal-to-ligand stoichiometric ratio in $\mathbf{5}$ equals 1:2. The closest structural analogues of $\mathbf{5}$ reported in the literature are the 
hexafluorophosphate salts of the tetrakis $\left(N, N, N^{\prime}, N^{\prime}\right.$-tetramethylmalonamide) complexes of samarium(III) and erbium(III) [27] and the perrhenate salt of the tetrakis $\left(N, N, N^{\prime}, N^{\prime}-\right.$ tetraethylmalonamide) complex of neodymium(III) [28]. In these complexes the metal ions have coordination environments that are formed by carbonyl oxygen atoms of four bidentate malonamide ligands, with the same geometry (i.e. square antiprisms) as that found in $\mathbf{5}$.

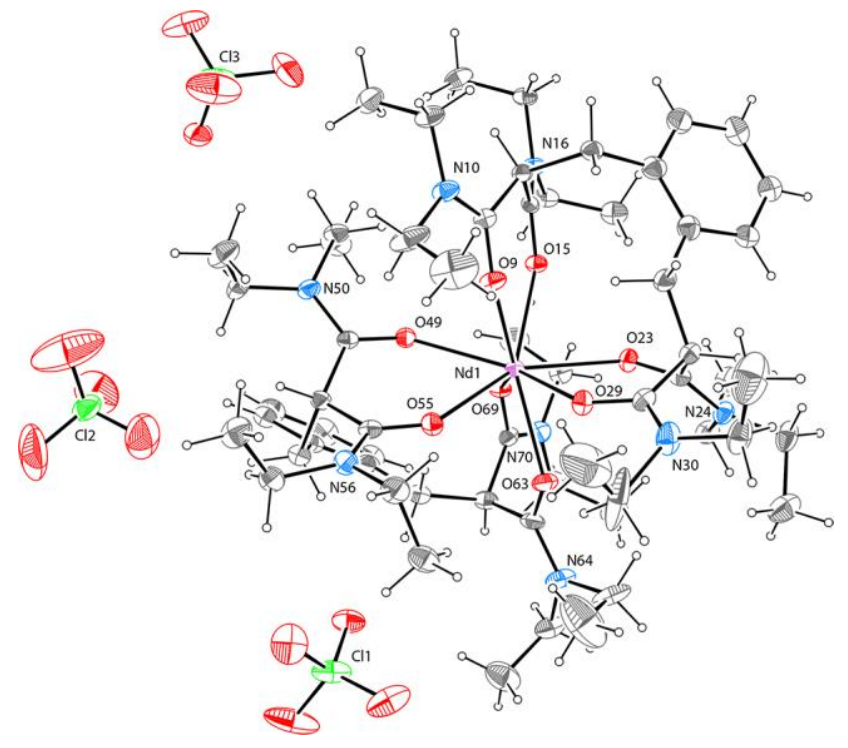

a

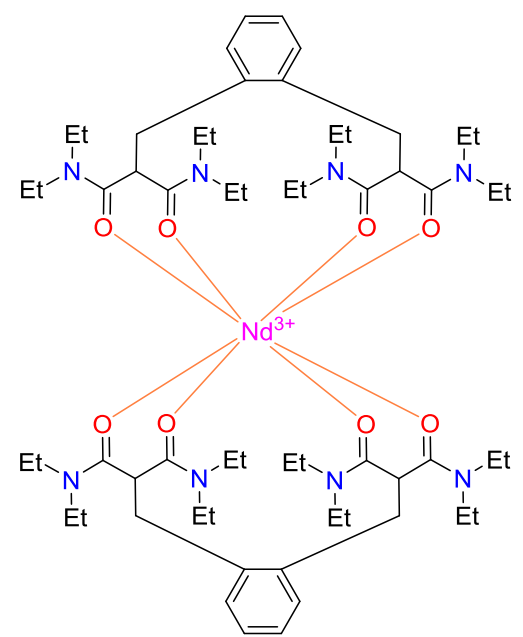

b

Figure 6 - The structure of $\left[\mathrm{NdL}_{2}\right] \cdot\left(\mathrm{ClO}_{4}\right)_{3} \cdot \mathrm{C}_{2} \mathrm{H}_{5} \mathrm{OH}(\mathbf{5})$ :

a - ORTEP drawing (30\% probability ellipsoids); carbon - gray, oxygen - red, nitrogen blue, hydrogen - white, chlorine - green; molecules of solvent $\left(\mathrm{C}_{2} \mathrm{H}_{5} \mathrm{OH}\right)$ have been omitted for clarity; $b$ - chemical diagram of the cation $\left[\mathrm{NdL}_{2}\right]^{3+}$ of $\mathbf{5}$.

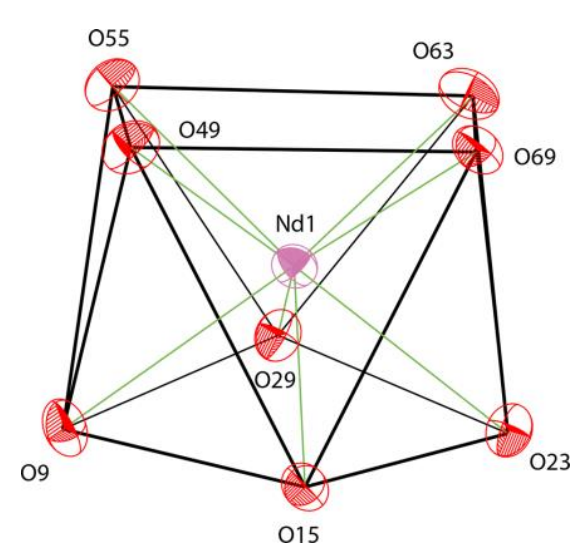

a

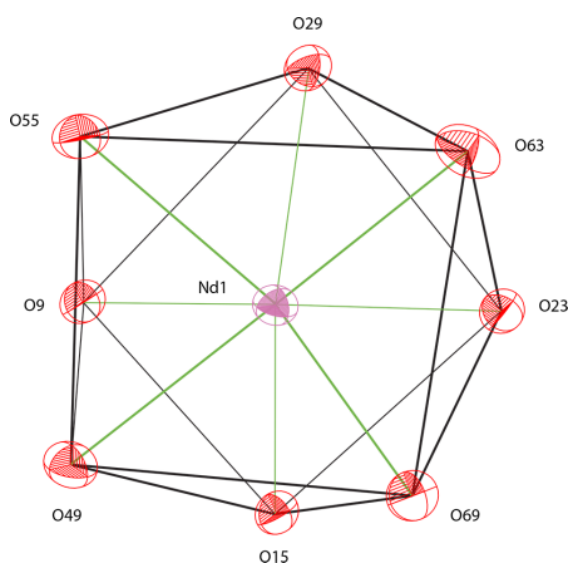

b

Figure 7. The coordination polyhedron of the $\mathrm{Nd}^{3+}$ ion in $\mathbf{5}$ (square antiprism): $\mathrm{a}$ - side view; $\mathrm{b}$ - top view. 
The reduction of the $\mathrm{Nd}(\mathrm{III})$ coordination when changing from the structure $\mathbf{2}$ to $\mathbf{5}$ is accompanied by a decrease in the bond distances of neodymium(III) with the carbonyl oxygen atoms of the $N, N, N^{\prime}, N^{\prime}$-tetraethylmalonamide units from [2.415(3) - 2.530(4)] $\AA$ in 2 to [2.384(3) - 2.478(4)] $\AA$ in 5 (Table S1). However these distances are the shortest in the structure 3: $[2.357(2)-2.421(2)] \AA$ and $[2.361(3)-2.417(3)] \AA$, which indicates the stronger binding of bismalonamide $\mathbf{1 b}$ with 9-coordinate neodymium(III) ions.

Although perchlorate based industrial liquid-liquid extraction systems for metals may not be attractive for safety reasons, this weakly-coordinating anion can be used to provide valuable structural information from its complexes with metals. Thus the structure $\mathbf{5}$ proves that the bismalonamide ligand can be tetradentate.

\section{On the denticity of the bismalonamide $1 \mathrm{~b}$ in its crystal complexes with lanthanides(III).}

Each of the crystal structures $\mathbf{2 - 5}$ has a specific coordination of ortho-bismalonamide $\mathbf{1 b}$ with a lanthanide(III) ion. It illustrates the complexity and diversity of the coordination chemistry of the bismalonamide ligands. These structures elucidate the essential question of the denticity of the ortho-bismalonamides in their complexes with trivalent lanthanides.

In the structure $\mathrm{Ce}\left(\mathrm{NO}_{3}\right)_{3} \cdot \mathrm{L}_{2}$ (4) bismalonamide $\mathbf{1 b}$ acts as a bidentate ligand, being an equivalent of a conventional bidentate malonamide in the sense of the metal coordination. Thus, despite possessing four potentially coordinating carbonyl oxygen atoms, bismalonamide $\mathbf{1 b}$ does not attain the principle of the polydenticity in the structure 4. Therefore no entropyinduced energy gain can be expected for such coordination. In the crystal complex $\left[\mathrm{NdL}_{2}\right] \cdot\left(\mathrm{ClO}_{4}\right)_{3} \cdot \mathrm{C}_{2} \mathrm{H}_{5} \mathrm{OH}(\mathbf{5})$ bismalonamide $\mathbf{1 b}$ is tetradentate. Both malonamide units of the ligand are involved in coordination with neodymium(III) central ion. This structure presents the first reported crystallographic evidence of the polydentate coordination of the bismalonamides with trivalent lanthanides. The coordination of $\mathbf{1 b}$ with $\mathrm{Nd}(\mathrm{III})$ ions in the structures $\left[\mathrm{Nd}_{2}\left(\mathrm{NO}_{3}\right)_{6} \cdot \mathrm{L}_{2}\right] \cdot\left(\mathrm{CH}_{3} \mathrm{CN}\right)_{3}(2)$ and $\left[\mathrm{Nd}_{2}\left(\mathrm{NO}_{3}\right)_{4} \mathrm{~L}_{2}\right] \cdot\left[\mathrm{Nd}\left(\mathrm{NO}_{3}\right)_{5}\right] \cdot\left(\mathrm{CH}_{3} \mathrm{CN}\right)_{1.5}$ (3) is somewhat intermediate between the coordination modes in $\mathbf{4}$ and $\mathbf{5}$. In the structures $\mathbf{2}$ and $\mathbf{3}$ each neodymium(III) ion is bonded with two bidentate malonamide groups from two molecules of $\mathbf{1 b}$, like central cerium(III) ion in $\mathbf{4}$. Hence bismalonamide $\mathbf{1 b}$ is the bidentate ligand in the structures $\mathbf{2}$ and $\mathbf{3}$ with respect to an individual Nd(III) ion. However the structures $\mathbf{2}$ and $\mathbf{3}$ are composed of the macrocyclic dimers. Both malonamide groups of each molecule of $\mathbf{1 b}$ are involved in the coordination with $\mathrm{Nd}(\mathrm{III})$ ions in these dimers, which means that bismalonamide $\mathbf{1 b}$ is tetradentate in $\mathbf{2}$ and $\mathbf{3}$, though not coordinating to one central ion with all four carbonyl oxygen atoms. 
An important conclusion can be drawn from the structures 2-5 regarding the effect of a counterion on the coordination of the ortho-bismalonamides with trivalent lanthanides. In the structure 5 perchlorate anions do not coordinate with a lanthanide(III) ion, thus prompting bismalonamide ligands to fill up its coordination sites in a polydentate manner. $\mathrm{Bi}$ - and tridentate nitrate anions in the structures 2-4 do coordinate to a lanthanide(III) ion and occupy five to six coordination sites of it, reducing (but not eliminating) the chances of the orthobismalonamide for a polydentate coordination with a metal ion. In general the polydentate coordination mode of the bismalonamides with trivalent lanthanides should be more common for a medium with a weakly coordinating counter-ion.

The information on the compositions of the structures 2-5 was obtained from single-crystal XRD analysis. The stoichiometric ratio of neodymium(III) to bismalonamide $\mathbf{1 b}$ in the structure $\mathbf{2}$ and in the cation of $\mathbf{3}$ is 2:2, however it is reduced to 1:1 for the empirical metal-to-ligand ratio. The structures $\mathbf{4}$ and $\mathbf{5}$ have identical 1:2 lanthanide(III)-bismalonamide 1b stoichiometric ratios in spite of the fact that the coordination modes in these complexes are completely different. The slope analysis, routinely used to establish the composition of the extracted metal species $[13,14]$, would be incapable of neither the recognition of the dimeric character of the lanthanide species in $\mathbf{2}$ and $\mathbf{3}$ nor the distinguishing between the structures in the pairs $\mathbf{2 - 3}$ and 4-5 with the isostoichiometric compositions, which emphasizes the importance of the collected coordination data for the structures 2-5.

\section{Electrospray Ionization - Mass Spectrometry.}

The analysis of the compounds 2-5 with single-crystal XRD allowed us to examine the coordination of trivalent lanthanide ions with the ortho-bismalonamide $\mathbf{1 b}$ in a solid state. To be able to know how far the collected crystallography data can be applied for an explanation of a liquid-liquid extraction of lanthanides with ortho-bismalonamides such as $\mathbf{1 a}$, the speciation of the solution-state metal complexes with a bismalonamide ligand is needed.

In the method of slow solvent evaporation, used to obtain crystal structures $\mathbf{2 - 5}$, a solid-state metal complex (i.e. a crystal) is evolving under continuous exchange of a matter with solutionstate metal complexes. Therefore the genesis and the mutual transformations of solid- and solution-state complexes can be best established from the analysis of a mother liquor for the respective crystals. In our work the speciation analysis of the lanthanide(III)-bismalonamide complexes was carried out by electrospray ionization - mass spectrometry (ESI-MS) for those acetonitrile solutions that were used to prepare single-crystals. The solutions were diluted with acetonitrile before the measurements as required by the method. 
The ESI-MS technique is widely used to investigate the metal-ligand interactions, namely to determine precisely the composition of the complexes in solutions, since it enables to preserve and transport metal-ligand complexes from a solution to a gas phase [29-31].

Since neodymium is a central atom in the crystal structures $\mathbf{2}$ and $\mathbf{3}$, this metal was selected for the ESI-MS analysis of its nitrato complexes with bismalonamide $\mathbf{1 b}$ in acetonitrile solutions. The complicated isotopic composition of neodymium, which has seven naturally occurring isotopes: Nd-142 (27.13\%), Nd-143 (12.18\%), Nd-144 (23.80\%), Nd-145 (8.30\%), Nd-146 (17.19\%), Nd-148 (5.76\%), Nd-150 (5.64\%) [32], makes the recorded ESI-mass spectra of its complexes with bismalonamide $\mathbf{1 b}$ being inconvenient for analysis (these spectra can be found in the Supporting Information). On the other hand praseodymium, adjacent to neodymium in the Periodic Table of the Elements, has very similar chemical properties and therefore should form solution-state complexes of the same composition. Naturally occurring praseodymium has only one isotope Pr-141 (100\%) [32], which facilitates the analysis of ESI-mass spectra. We recorded the ESI-mass spectra of the praseodymium(III) complexes with bismalonamide $\mathbf{1 b}$ in acetonitrile and compared it with those for neodymium. This comparison demonstrated clearly that the speciation of the lanthanide(III) complexes is identical for both metal ions. For the sake of conciseness we discuss further only the ESI-mass spectra of praseodymium(III) complexes with bismalonamide $\mathbf{1 b}$.

Positive electrospray ionization - mass spectra were recorded for the bismalonamide $\mathbf{1 b}$ solution and for two solutions of praseodymium(III) nitrate and bismalonamide $\mathbf{1 b}$ with the 1:1 and 1:2 metal-to-ligand molar ratios, respectively. All spectra were recorded in acetonitrile (Figure 8). 


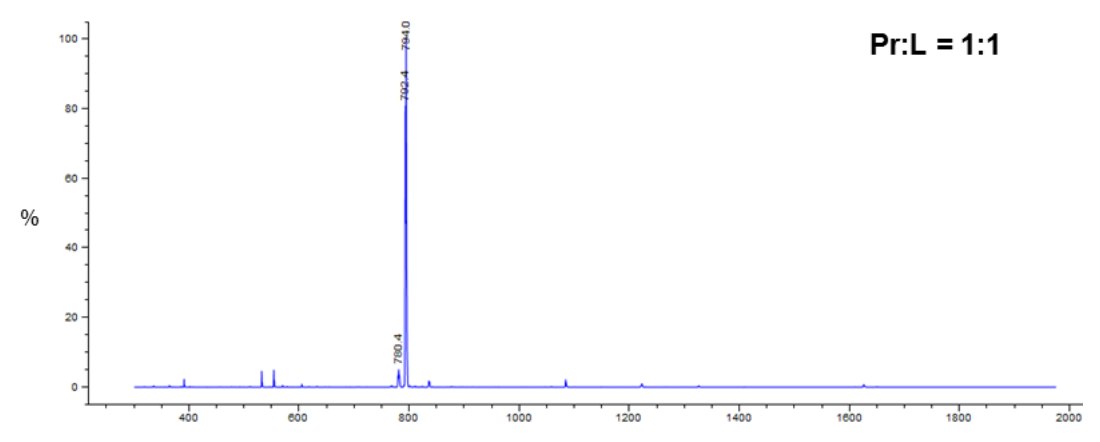

$\mathrm{m} / \mathrm{z}$

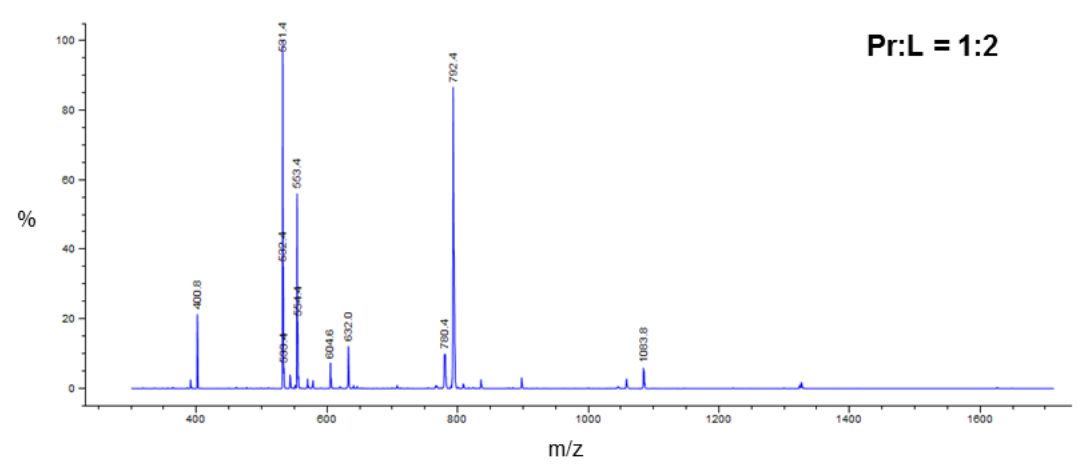

Figure 8. Positive ESI-mass spectra of the solutions of $\operatorname{Pr}\left(\mathrm{NO}_{3}\right)_{3}$ and bismalonamide $\mathbf{1 b}(\mathrm{L})$ with the 1:1 and 1:2 metal-to-ligand molar ratios.

The spectra were recorded in acetonitrile with the addition of acetic acid.

Three groups of peaks were detected in the mass spectrum of bismalonamide $\mathbf{1 b}(\mathrm{L})$ in acetonitrile (Supporting Information, Figure S3). The peaks at $\mathrm{m} / \mathrm{z}=531.4$ and 532.4 correspond to the protonated form of the ligand $[\mathrm{LH}]^{+}$. The peaks at $\mathrm{m} / \mathrm{z}=553.4$ and 554.4 are assigned to the sodium complex with the ligand $[\mathrm{LNa}]^{+}$. The less abundant species having $\mathrm{m} / \mathrm{z}$ $=604.6$ and 605.6 were not identified. All these peaks can be observed in both solutions of praseodymium(III) having the 1:1 and 1:2 metal-to-ligand molar ratios (Figure 8). When the initial concentration of the ligand is high enough, like in the solution with $\operatorname{Pr}: \mathrm{L}=1: 2$, one more sodium complex with the ligand $\left[\mathrm{L}_{2} \mathrm{Na}\right]^{+}(\mathrm{m} / \mathrm{z}=1083.8)$ is being formed. It is worth mentioning here that the $\mathrm{H}^{+}$ions come from acetic acid added to the samples, while $\mathrm{Na}^{+}$is leached out from glass.

In the equimolar (1:1) solution of $\operatorname{Pr}$ and the ligand the complexes with $\mathrm{m} / \mathrm{z}=792.4$ and 794.0 are dominating (Figure 8). However the formation of the minor species with $\mathrm{m} / \mathrm{z}=780.4$ was also noticed. The spectrum of the solution with the higher fraction of the ligand, i.e. with $\operatorname{Pr}: \mathrm{L}$ $=1: 2$, is more diverse and contains peaks of the complexes with $\mathrm{m} / \mathrm{z}=400.8 ; 632.0 ; 780.4$ and 792.4 (Figure 8). In order to identify these species positive high-resolution ESI-mass spectra of the praseodymium(III) complexes were recorded for both solutions (Figure 9). 

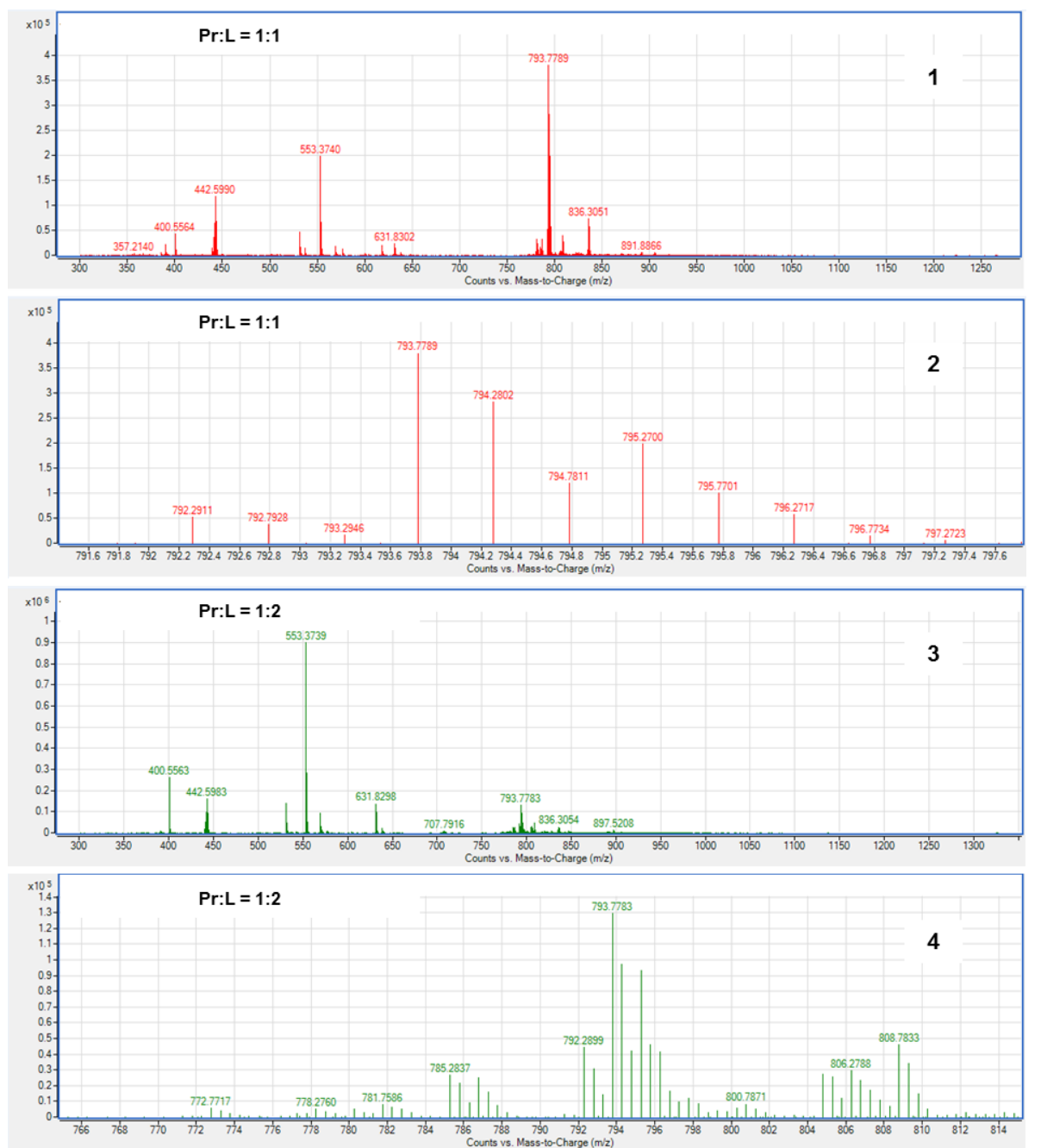

Figure 9. Positive high-resolution ESI-mass spectra of the solutions of $\operatorname{Pr}\left(\mathrm{NO}_{3}\right)_{3}$ and bismalonamide 1b (L) with the 1:1 and 1:2 metal-to-ligand molar ratios. The spectra were recorded in acetonitrile with the addition of acetic acid.

The identified praseodymium(III) species are listed in Table 1.

Table 1 - Praseodymium(III) complexes with bismalonamide 1b (L) detected by ESI-MS in acetonitrile.

\begin{tabular}{|c|c|c|c|c|c|}
\hline \multirow{2}{*}{ Complex } & \multirow{2}{*}{$\begin{array}{c}\text { Exact mass, } \\
\text { a.m.u. }\end{array}$} & \multicolumn{2}{|c|}{$\mathbf{m} / \mathbf{z}$} & \multirow{2}{*}{$\begin{array}{c}\Delta(\mathbf{m} / \mathbf{z})^{*} \\
\mathbf{p p m}\end{array}$} & \multirow{2}{*}{$\begin{array}{c}\text { Mass } \\
\text { intensity } \\
\text { (theor.), } \\
\%\end{array}$} \\
\hline & & experimental & theoretical & & \\
\hline \multirow{2}{*}[\mathrm{PrL}_{3}\mathrm{NO}_{3}]{$^{2+}$} & \multirow{2}{*}{1794.0451} & \multirow{2}{*}{897.5208} & 897.0226 & - & 100.0 \\
\hline & & & 897.5243 & 3.9 & 97.3 \\
\hline \multirow{3}{*}[\mathrm{PrL}_{2}]{$^{3+}$} & \multirow{3}{*}{1201.6741} & \multirow{3}{*}{400.5564} & 400.5580 & 4.0 & 100.0 \\
\hline & & & 400.8925 & - & 64.9 \\
\hline & & & 401.2269 & - & 20.7 \\
\hline
\end{tabular}




\begin{tabular}{|c|c|c|c|c|c|}
\hline \multirow{3}{*}[\mathrm{PrL}_{2}\mathrm{NO}_{3}]{$^{2+}$} & \multirow{3}{*}{1263.6619} & \multirow{3}{*}{631.8302} & 631.8310 & 1.3 & 100.0 \\
\hline & & & 632.3327 & - & 64.9 \\
\hline & & & 632.8343 & - & 20.7 \\
\hline \multirow{3}{*}[\mathrm{PrL}_{2}(\mathrm{NO}_{3})_{2}]{$^{+}$} & \multirow{3}{*}{1325.6497} & \multirow{3}{*}{$1320-1330$} & 1325.6498 & - & 100.0 \\
\hline & & & 1326.6531 & - & 64.9 \\
\hline & & & 1327.6565 & - & 20.7 \\
\hline \multirow{3}{*}[\operatorname{PrL}(\mathrm{NO}_{3})_{2}]{$^{+* *}$} & \multirow{3}{*}{795.2665} & 795.2700 & 795.2666 & 4.3 & 100.0 \\
\hline & & 796.2717 & 796.2699 & 2.3 & 32.4 \\
\hline & & 797.2733 & 797.2733 & 0.0 & 5.1 \\
\hline \multirow{4}{*}[\mathrm{Pr}_{2}\mathrm{L}_{2}(\mathrm{NO}_{3})_{4}]{$^{2+}$} & \multirow{4}{*}{1590.5330} & 795.2700 & 795.2666 & 4.3 & 100.0 \\
\hline & & 795.7701 & 795.7682 & 2.4 & 64.9 \\
\hline & & 796.2717 & 796.2699 & 2.3 & 20.7 \\
\hline & & 796.7734 & 796.7659 & 9.4 & 4.3 \\
\hline \multirow{3}{*}[\mathrm{Pr}_{2}\mathrm{L}_{2}(\mathrm{NO}_{3})_{3}(\mathrm{CH}_{3}\mathrm{COO})]{$^{2+}$} & \multirow{3}{*}{1587.5585} & 793.7789 & 793.7793 & 0.5 & 100.0 \\
\hline & & 794.2802 & 794.2810 & 1.0 & 67.1 \\
\hline & & 794.7811 & 794.7826 & 1.9 & 22.1 \\
\hline \multirow{2}{*}[\operatorname{PrL}(\mathrm{NO}_{3})(\mathrm{CH}_{3}\mathrm{COO})]{$^{+* *}$} & \multirow{2}{*}{792.2920} & 792.2899 & 792.2920 & 2.7 & 100.0 \\
\hline & & 793.2921 & 793.2954 & 4.2 & 34.6 \\
\hline \multirow{3}{*}[\mathrm{Pr}_{2}\mathrm{L}_{2}(\mathrm{NO}_{3})_{2}(\mathrm{CH}_{3}\mathrm{COO})_{2}]{$^{2+}$} & \multirow{3}{*}{1584.5840} & 792.2911 & 792.2920 & 1.1 & 100.0 \\
\hline & & 792.7928 & 792.7937 & 1.1 & 69.2 \\
\hline & & 793.2946 & 793.2954 & 1.0 & 23.6 \\
\hline
\end{tabular}

${ }^{*} \Delta(m / z)=\left|\frac{(m / z)_{\text {theor. }}-(m / z)_{\text {exper. }}}{(\mathrm{m} / \mathrm{z})_{\text {theor. }}}\right| \times 10^{6}$

** - possible species

All praseodymium(III) complexes with bismalonamide 1b, detected by ESI-MS, have the metal-to-ligand molar ratios of either $1: 1$ or $1: 2$, with one exception of the $1: 3$ ratio in $\left[\mathrm{PrL}_{3} \mathrm{NO}_{3}\right]^{2+}$. This complex with unusual stoichiometry was observed only in the $\operatorname{Pr}(\mathrm{III})$ solution with higher initial concentration of the ligand.

As one can expect the dominating species in the equimolar (1:1) solution of $\operatorname{Pr}$ and bismalonamide $\mathbf{1 b}$ have the equimolar metal-to-ligand ratio of 1:1. However these complexes surprisingly were found to be the dimers $\left[\operatorname{Pr}_{2} \mathrm{~L}_{2}\left(\mathrm{NO}_{3}\right)_{4}\right]^{2+},\left[\operatorname{Pr}_{2} \mathrm{~L}_{2}\left(\mathrm{NO}_{3}\right)_{3}\left(\mathrm{CH}_{3} \mathrm{COO}\right)\right]^{2+}$ and $\left[\mathrm{Pr}_{2} \mathrm{~L}_{2}\left(\mathrm{NO}_{3}\right)_{2}\left(\mathrm{CH}_{3} \mathrm{COO}\right)_{2}\right]^{2+}$ with the 2:2 metal-to-ligand stoichiometry (Table 1). The asymmetric complex $\left[\mathrm{Pr}_{2} \mathrm{~L}_{2}\left(\mathrm{NO}_{3}\right)_{3}\left(\mathrm{CH}_{3} \mathrm{COO}\right)\right]^{2+}$ has the highest relative concentration among other dimers in the solution. The collected high-resolution ESI-MS spectra of the dimeric 
species allow one to distinguish them clearly from all other detected or hypothetical praseodymium(III) complexes with the ligand e.g. mononuclear species or polymers of the higher order (trimers, tetramers etc.). The minor species $\left[\mathrm{PrL}_{2}\right]^{3+}$ and $\left[\mathrm{PrL}_{2}\left(\mathrm{NO}_{3}\right)_{2}\right]^{+}$were also detected in the solution (Figure 9).

In the acetonitrile solution with the 1:2 initial molar ratio of praseodymium(III) to bismalonamide $\mathbf{1 b}$ the dimers $\left[\mathrm{Pr}_{2} \mathrm{~L}_{2}\left(\mathrm{NO}_{3}\right)_{4}\right]^{2+}, \quad\left[\mathrm{Pr}_{2} \mathrm{~L}_{2}\left(\mathrm{NO}_{3}\right)_{3}\left(\mathrm{CH}_{3} \mathrm{COO}\right)\right]^{2+}$ and $\left[\mathrm{Pr}_{2} \mathrm{~L}_{2}\left(\mathrm{NO}_{3}\right)_{2}\left(\mathrm{CH}_{3} \mathrm{COO}\right)_{2}\right]^{2+}$ remain to be one of the major metal species (Figure 8). However the fractions of the 1:2 ligand-rich complexes $\left[\mathrm{PrL}_{2}\right]^{3+}$ and $\left[\mathrm{PrL}_{2} \mathrm{NO}_{3}\right]^{2+}$ are higher in this solution than in the equimolar solution with $\operatorname{Pr}: \mathrm{L}=1: 1$ (Figure 9). It can be explained by the right shift of the praseodymium(III)-bismalonamide $\mathbf{1 b}$ reaction equilibria (1) and (2) in the $\operatorname{Pr}: \mathrm{L}=1: 2$ solution, caused by an increase of the initial ligand concentration at fixed initial concentration of the metal:

$$
\begin{gathered}
\mathrm{Pr}^{3+}+2 \mathrm{~L} \leftrightarrow\left[\mathrm{PrL}_{2}\right]^{3+} \\
\mathrm{Pr}^{3+}+\mathrm{NO}_{3}{ }^{-}+2 \mathrm{~L} \leftrightarrow\left[\mathrm{PrL}_{2} \mathrm{NO}_{3}\right]^{2+}
\end{gathered}
$$

The presence of the praseodymium(III) dimeric complexes in both solutions obscures the formation of the corresponding mononuclear species $\left[\operatorname{PrL}\left(\mathrm{NO}_{3}\right)_{2}\right]^{+}$and $\left[\operatorname{PrL}\left(\mathrm{NO}_{3}\right)\left(\mathrm{CH}_{3} \mathrm{COO}\right)\right]^{+}$. Thus the ESI-MS spectrum of the monomer $\left[\operatorname{PrL}\left(\mathrm{NO}_{3}\right)_{2}\right]^{+}$fully coincides with that of the dimer $\left[\mathrm{Pr}_{2} \mathrm{~L}_{2}\left(\mathrm{NO}_{3}\right)_{4}\right]^{2+}$ for the exception of two peaks at $\mathrm{m} / \mathrm{z}=$ 795.7701 (theoretical mass intensity 64.9\%) and 796.7734 attributed exclusively to the dimer. Therefore it is hard to confirm or rule out the existence of the mononuclear species $\left[\mathrm{PrL}\left(\mathrm{NO}_{3}\right)_{2}\right]^{+}$ in the acetonitrile solutions. However from the experimental ratios of intensities of the $\mathrm{m} / \mathrm{z}$ peaks of the dimers it is clear that the mononuclear complexes, if they do exist in the solutions, could be minor species only. This conclusion is applicable to the complex $\left[\operatorname{PrL}\left(\mathrm{NO}_{3}\right)\left(\mathrm{CH}_{3} \mathrm{COO}\right)\right]^{+}$for the same reasons.

\section{Comparison of results obtained by different methods.}

M.T. Murillo et al. has demonstrated earlier that the bismalonamide ligands can extract europium(III) ions from aqueous solutions with higher distribution ratios than the related bidentate malonamides [13]. It was suggested that the higher distribution ratios of lanthanide(III) ions with the bismalonamides could result from favorable entropy changes in the metal extraction reaction, assuming that the bismalonamides were extracting trivalent lanthanide ions as the tetradentate ligands [13]. However neither of these two hypotheses have been tested experimentally. So far no research was conducted on the coordination of the 
polydentate malonamide ligands, including bismalonamides, with lanthanide(III) ions, which is regarded as the obstacle for the development of this type of liquid-liquid extraction ligands [13].

In our work single-crystal XRD and ESI-MS analyses of the lanthanide(III) complexes with ortho-bismalonamide $\mathbf{1 b}$ were conducted in order to allow us to compare the complexation of 1b in the solid and solution states. We wished to use this data to explain the liquid-liquid extraction of lanthanide(III) ions with ortho-bismalonamides. Firstly it is important to decide if the crystallographic results are relevant to the liquid-liquid extraction of the lanthanides. To determine if the formation of the solid species was due to crystal packing effects the ESI-mass spectroscopy experiments were performed using solutions identical to those used for growing crystals. We assume that the dimers $\left[\mathrm{Pr}_{2} \mathrm{~L}_{2}\left(\mathrm{NO}_{3}\right)_{4}\right]^{2+}, \quad\left[\mathrm{Pr}_{2} \mathrm{~L}_{2}\left(\mathrm{NO}_{3}\right)_{3}\left(\mathrm{CH}_{3} \mathrm{COO}\right)\right]^{2+}$ and $\left[\mathrm{Pr}_{2} \mathrm{~L}_{2}\left(\mathrm{NO}_{3}\right)_{2}\left(\mathrm{CH}_{3} \mathrm{COO}\right)_{2}\right]^{2+}$, existing in acetonitrile solutions, are related to the dimers in the crystal structures $\left[\mathrm{Nd}_{2}\left(\mathrm{NO}_{3}\right)_{6} \cdot \mathrm{L}_{2}\right] \cdot\left(\mathrm{CH}_{3} \mathrm{CN}\right)_{3}(2)$ or $\left[\mathrm{Nd}_{2}\left(\mathrm{NO}_{3}\right)_{4} \mathrm{~L}_{2}\right] \cdot\left[\mathrm{Nd}\left(\mathrm{NO}_{3}\right)_{5}\right] \cdot\left(\mathrm{CH}_{3} \mathrm{CN}\right)_{1.5}(3)$, evolved from the respective acetonitrile solution. The complexes $\left[\mathrm{PrL}_{2}\right]^{3+},\left[\mathrm{PrL}_{2} \mathrm{NO}_{3}\right]^{2+}$ and $\left[\mathrm{PrL}_{2}\left(\mathrm{NO}_{3}\right)_{2}\right]^{+}$, detected by the ESI-MS in acetonitrile, are likely to be related to the crystal structures $\mathrm{Ce}\left(\mathrm{NO}_{3}\right)_{3} \cdot \mathrm{L}_{2}(\mathbf{4})$ or $\left[\mathrm{Nd} \cdot \mathrm{L}_{2}\right] \cdot\left(\mathrm{ClO}_{4}\right)_{3} \cdot \mathrm{C}_{2} \mathrm{H}_{5} \mathrm{OH}(\mathbf{5})$. The observation of species by both techniques lead us to the conclusion that the crystal structures 2-5 are not due to a specific feature of the crystallization process.

It is important to mention that the lanthanide(III) complexes, identified by XRD and ESI-MS, are formed under specific experimental conditions i.e. high metal-to-ligand ratios, which are not typical for liquid-liquid extraction of the metal ions. Therefore caution must be taken when the XRD and ESI-MS data is applied for an explanation of a liquid-liquid extraction of a metal ion. It might be possible to observe the existence of a polynuclear species, including dimers, by liquid-liquid extraction tests. The formation of the solution-state polynuclear complexes and aggregates of lanthanides with conventional bidentate malonamide ligands at high metal concentrations has been described by R.J. Ellis et al. [33, 34] and M.R. Antonio et al. [35]. The formation of the dimers, such as $\left[\operatorname{Pr}_{2} \mathrm{~L}_{2}\left(\mathrm{NO}_{3}\right)_{4}\right]^{2+}$, in an organic phase of a liquid-liquid extraction system in a nitrate medium can be described by the reaction equation:

$$
2 \mathrm{Ln}^{3+}{ }_{(\mathrm{aq})}+6 \mathrm{NO}_{3}^{-{ }_{(\mathrm{aq})}}+2 \mathrm{~L}_{(\mathrm{org})} \leftrightarrow\left[\mathrm{Ln}_{2}\left(\mathrm{NO}_{3}\right)_{6} \cdot \mathrm{L}_{2}\right]_{(\mathrm{org})},
$$

where Ln and L represent a lanthanide ion and a bismalonamide molecule respectively, and the subscripts (aq) and (org) correspond to the aqueous and the organic phases of the extraction system, respectively. The equilibrium constant $\mathrm{K}_{\mathrm{ex}}$ of the reaction (3) is defined by the equation: 


$$
K_{e x}=\frac{\left[\operatorname{Ln}_{2}\left(\mathrm{NO}_{3}\right)_{6} \cdot \mathrm{L}_{2}\right]_{o r g}}{\left[\mathrm{Ln}^{3+}\right]_{a q}^{2} \times\left[\mathrm{NO}_{3}{ }^{-}\right]_{a q}^{6} \times[L]^{2}{ }_{\text {org }}},
$$

where the square brackets stand for the activities of the corresponding species.

The distribution ratio (D) of a lanthanide ion is described by the equation:

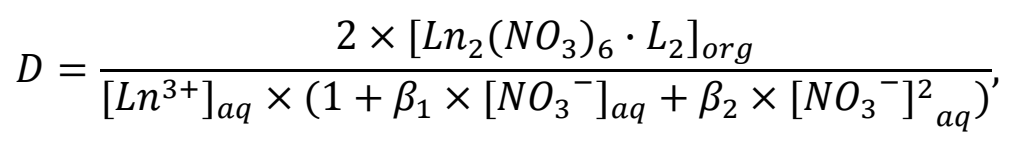

where $\beta_{1}$ and $\beta_{2}$ are the stability constants of the nitrate complexes of $\operatorname{Ln}(\mathrm{III})$ in an aqueous phase.

From the equations (4) and (5) one can derive a new equation which suggests that a distribution ratio should be proportional to an equilibrium metal concentration in an aqueous phase provided that the dimers are the dominant species in an organic phase:

$$
D=\left(\frac{2 \times K_{e x} \times\left[\mathrm{NO}_{3}{ }^{-}\right]_{a q}^{6} \times[L]^{2}{ }_{\text {org }}}{1+\beta_{1} \times\left[\mathrm{NO}_{3}{ }^{-}\right]_{a q}+\beta_{2} \times\left[\mathrm{NO}_{3}{ }^{-}\right]_{a q}^{2}}\right) \times\left[L n^{3+}\right]_{a q} .
$$

As long as the nitrate concentration in the aqueous phase remains constant, the complexation of nitrate to the lanthanide will not prevent the distribution ratio being proportional to the lanthanide concentration. However the liquid-liquid extraction experiment, in which the lanthanide concentration was varied, demonstrated that the distribution ratios of neodymium and ytterbium were not dependent on the equilibrium metal concentration in an aqueous phase (Figure 10). These results indicate that the dimers of the bismalonamide 1a and lanthanide(III) ions were not being formed under the selected experimental conditions. Also when the diluent of an organic phase was nitrobenzene no evidence for the dimer formation was observed by liquid-liquid extraction [16]. 


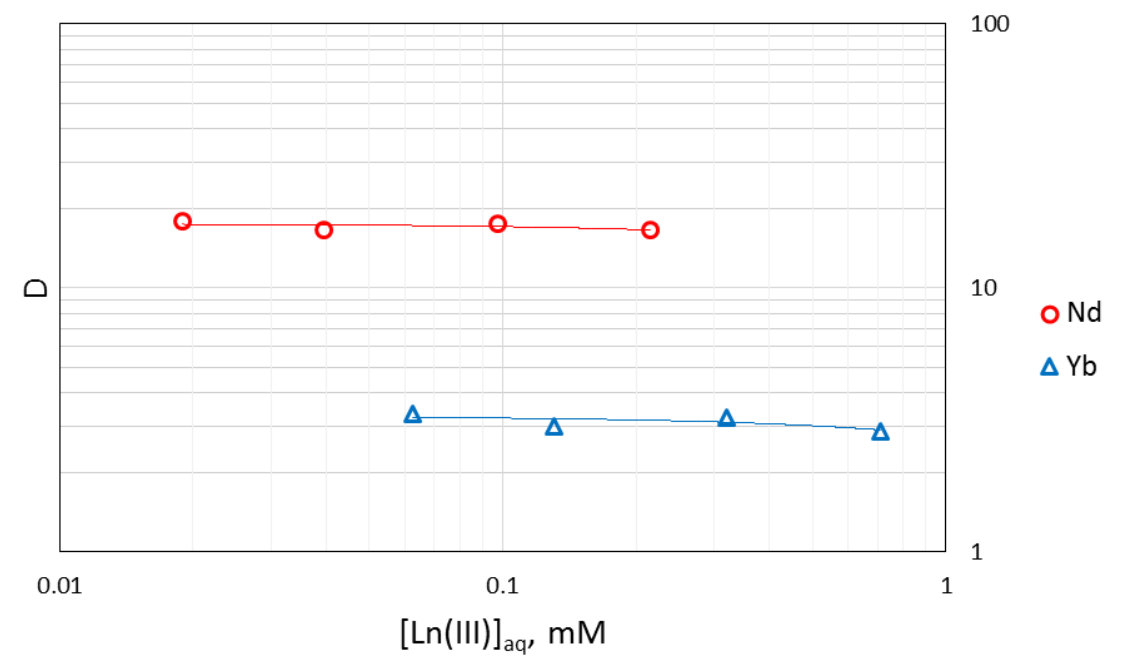

Figure 10. Distribution ratios of neodymium(III) and ytterbium(III) as a function of an equilibrium metal concentration in an aqueous phase. Aq. phase: $3 \mathrm{M} \mathrm{HNO}_{3}$; org. phase: 0.36 M bismalonamide 1a in Solvesso $150 \mathrm{ND}$ (aromatic kerosene).

We reason that the formation of the dimers in acetonitrile is governed by concentrations of a metal and the ligand (Figures 8 and 9). We conclude that in liquid-liquid extraction processes the dimers could be formed only at exceptionally high metal loading of an organic phase, however a failure to observe an effect is not itself a proof that the effect does not exist. The dimeric lanthanide complexes obtained in our work expand the conventional view on the coordination of multicoordinate ligands with metal ions despite this particular coordination occurs under specific conditions.

It is commonly accepted that multicoordinate ligands, such as the bismalonamides, extract metal ions with higher distribution ratios, than ligands which have the same donor atoms but with lower denticities, for entropic reasons $[12,13]$. For an entropic advantage to exist the bismalonamides must act as tetradentate ligands towards a metal ion. The tetradentate coordination of bismalonamide $\mathbf{1 b}$ with $\mathrm{Nd}$ (III) was realized in the structure $\mathbf{5}$, which confirms on the qualitative level that the entropy-favorable coordination of lanthanide(III) ions with bismalonamide ligands is possible.

The combination of single-crystal X-ray diffractometry, electrospray ionization - mass spectrometry and liquid-liquid extraction for the studies of the lanthanide(III)-bismalonamide complexes rewarded us with better understanding of the coordination chemistry of the bismalonamides with trivalent $4 \mathrm{f}$-block elements. Our results may assist the development of this group of liquid-liquid extraction ligands and indicate that thermodynamic data is required for further contribution to this goal. 


\section{Experimental Section}

\section{Materials and Instruments.}

The reagents for syntheses were purchased from Aldrich and were used as supplied. The purity of all reagents used was at least $97 \% . N, N, N^{\prime}, N^{\prime}$-tetraethylmalonamide was synthesized from malonyl chloride and diethylamine [5] and purified by vacuum distillation (b.p. $116-118{ }^{\circ} \mathrm{C}$ at 1 mbar) before use. The bismalonamide 2,2'-(1,2-phenylenebis(methylene)) bis $\left(N, N, N^{\prime}, N^{\prime}\right.$ tetrabutylmalonamide) (1a) was prepared as reported earlier [16]. Aromatic kerosene Solvesso $150 \mathrm{ND}\left(\mathrm{C}_{10}\right.$, aromatics, < $1 \%$ naphthalene), used as a diluent in liquid-liquid extraction experiments, was purchased from IsoChem AB (Sweden).

All nuclear magnetic resonance (NMR) experiments were performed using an Agilent400VNMRS400 (400 MHz) spectrometer (Agilent).

The infra-red (IR) spectrum was collected using a Nicolet 6700 FT-IR spectrometer (Thermo Scientific), equipped with a diamond attenuated total reflectance (ATR) cell. The resolution was set to $4 \mathrm{~cm}^{-1}$ and 64 scans of a sample were made for the FTIR spectrum recorded. When reporting infrared spectrum the following abbreviations were used to indicate the intensity of the absorption peaks: $\mathrm{v}$ - very, br. - broad, $\mathrm{m}$ - moderate, $\mathrm{s}$ - strong and $\mathrm{w}$ - weak.

Melting point was determined in glass capillaries using a Gallenkamp Melting Point Apparatus equipped with a liquid in glass thermometer. Melting point was uncorrected.

Inductively coupled plasma-mass spectrometer measurements were conducted using an iCAP Q spectrometer supplied by Thermo Scientific.

\section{Preparation of the bismalonamide $\mathbf{1 b}$.}

The ligand 2,2'-(1,2-phenylenebis(methylene)) bis( $N, N, N^{\prime}, N^{\prime}$-tetraethylmalonamide) (1b) was synthesized from $N, N, N^{\prime}, N^{\prime}$-tetraethylmalonamide and 1,2-bis(bromomethyl)benzene in tetrahydrofuran as previously described for 1a [16] .

Ligand 1b was isolated as a pale brown solid (64\% yield); m.p. (78-79) ${ }^{\circ} \mathrm{C} .{ }^{1} \mathrm{H}$ NMR $(400 \mathrm{MHz}$, $\left.\mathrm{CDCl}_{3}\right) \delta 0.99(\mathrm{t}, \mathrm{J}=7 \mathrm{~Hz}, 12 \mathrm{H}), 1.06(\mathrm{t}, \mathrm{J}=7.2 \mathrm{~Hz}, 12 \mathrm{H}), 3.00(\mathrm{~m}, 4 \mathrm{H}), 3.14(\mathrm{~m}, 4 \mathrm{H}), 3.25$ $(\mathrm{m}, 8 \mathrm{H}), 3.37(\mathrm{~m}, 4 \mathrm{H}), 4.09(\mathrm{t}, \mathrm{J}=7.2 \mathrm{~Hz}, 2 \mathrm{H}), 7.06(\mathrm{~m}, 4 \mathrm{H}) .{ }^{13} \mathrm{C} \mathrm{NMR}\left(400 \mathrm{MHz}, \mathrm{CDCl}_{3}\right) \delta$ 168.5, 137.3, 129.6, 126.6, 47.4 41.3, 40.1, 33.0, 13.6, 12.6. ATR-FTIR (wavenumber, $\mathrm{cm}^{-1}$ ): 2970(br. w), 2933(br. w), 2873(vw), 1639(s), 1620(br. vs), 1496(w), 1468(m), 1442(s), 1427(br. s), 1377(m), 1361(m), 1327(w), 1323(vw), 1309(w), 1281(m), 1263(m), 1244(vw), 1215(m), 1171(vw), 1146(w), 1126(m), 1090(br. m), 1041(vw), 1011(br. vw), 972(w), 955(m), 916(vw), 879(w), 860(w), 833(w), 764(br. m), 758(s), 708(vw), 710(vw), 665(w), 627(vw), 
611(m), 580(m). Anal. calcd. for $\mathrm{C}_{30} \mathrm{H}_{50} \mathrm{~N}_{4} \mathrm{O}_{4}: \mathrm{C}, 67.89 ; \mathrm{H}, 9.50 ; \mathrm{N}, 10.55 \%$. Found: C, 67.29; H, 9.85; N, 10.35 .

\section{Preparation of crystals of the lanthanide(III) complexes with the bismalonamide.}

Ligand $\mathbf{1 b}$ was used in all crystal growth experiments. For convenience this ligand is denoted further in the text as $\mathrm{L}$. The crystals of $\left[\mathrm{Nd}_{2}\left(\mathrm{NO}_{3}\right)_{6} \mathrm{~L}_{2}\right] \cdot\left(\mathrm{CH}_{3} \mathrm{CN}\right)_{3}$ (2), $\left[\mathrm{Nd}_{2}\left(\mathrm{NO}_{3}\right)_{4} \mathrm{~L}_{2}\right] \cdot\left[\mathrm{Nd}\left(\mathrm{NO}_{3}\right)_{5}\right] \cdot\left(\mathrm{CH}_{3} \mathrm{CN}\right)_{1.5}(3)$ and $\mathrm{Ce}\left(\mathrm{NO}_{3}\right)_{3} \mathrm{~L}_{2}(4)$ were obtained by the following method. The trinitrate salt of a respective lanthanide and ligand $\mathbf{1 b}$ were dissolved in acetonitrile $\left(\mathrm{CH}_{3} \mathrm{CN}\right)$ separately to give $0.5 \mathrm{M}$ and $1 \mathrm{M}$ solutions of $\mathrm{Ln}(\mathrm{III})$ and the ligand, respectively. Equal volumes $(1 \mathrm{~mL})$ of the two solutions were combined in a $20 \mathrm{~mL}$ glass vial equipped with a screw cap. The mixture was left overnight in a closed vial. The vial, without a cap, was then placed in a $100 \mathrm{~mL}$ glass vessel filled with $c a .10 \mathrm{~mL}$ of diethyl ether. The vessel was sealed with a plastic lid and crystals were obtained by solvent vapor diffusion at room temperature (23 $\pm 2)^{\circ} \mathrm{C}$ over $c a .24 \mathrm{~h}$. Crystals of $\mathbf{2}$ and $\mathbf{3}$ were harvested from the same vial. A similar method was used to prepare crystals of $\left[\mathrm{NdL}_{2}\right] \cdot\left(\mathrm{ClO}_{4}\right)_{3} \cdot \mathrm{C}_{2} \mathrm{H}_{5} \mathrm{OH}(\mathbf{5})$. In this case the metal and the ligand concentrations were reduced to $c a .0 .25 \mathrm{M}$ and $0.5 \mathrm{M}$, respectively, and a $1: 1(\mathrm{v} / \mathrm{v})$ mixture of acetonitrile and ethanol was used as a solvent. Neodymium perchlorate was obtained by reacting $\mathrm{Nd}_{2} \mathrm{O}_{3}(0.1269 \mathrm{~g})$ with perchloric acid $\left(0.4 \mathrm{~mL}, 70 \% \mathrm{HClO}_{4}\right)$ followed by dissolution in the acetonitrile-ethanol solvent and filtration $(25 \mathrm{~mm}$ syringe filter, $\mathrm{w} / 0.45 \mu \mathrm{m}$ polypropylene membrane, VWR). Caution: salts of perchloric acid are potentially explosive and should be handled accordingly [36].

\section{Single-crystal X-ray diffractometry.}

Representative crystals of $\quad\left[\mathrm{Nd}_{2}\left(\mathrm{NO}_{3}\right)_{6} \mathrm{~L}_{2}\right] \cdot\left(\mathrm{CH}_{3} \mathrm{CN}\right)_{3}$

$\left[\mathrm{Nd}_{2}\left(\mathrm{NO}_{3}\right)_{4} \mathrm{~L}_{2}\right] \cdot\left[\mathrm{Nd}\left(\mathrm{NO}_{3}\right)_{5}\right] \cdot\left(\mathrm{CH}_{3} \mathrm{CN}\right)_{1.5}(\mathbf{3}), \mathrm{Ce}\left(\mathrm{NO}_{3}\right)_{3} \mathrm{~L}_{2}(\mathbf{4})$ and $\left[\mathrm{NdL}_{2}\right] \cdot\left(\mathrm{ClO}_{4}\right)_{3} \cdot \mathrm{C}_{2} \mathrm{H}_{5} \mathrm{OH}(\mathbf{5})$ were selected and mounted in a loop. All measurements were made on a Rigaku XtaLAB P200 diffractometer using multi-layer mirror monochromated Mo-K $\alpha$ radiation (wavelength 0.71075 $\AA$ A). The collected reflections were processed using CrystalClear (Rigaku) [37] for the structures 2, 4, 5 and CrysAlis PRO 1.171.38.43i (Rigaku Oxford Diffraction) [38] for 3.

Empirical absorption corrections were applied to the linear absorption coefficients $\mu$ of the structures $\mathbf{2}, \mathbf{4}, \mathbf{5}$, and the data were corrected for Lorentz and polarization effects. The spherical harmonics, implemented in SCALE3 ABSPACK scaling algorithm, were used for correction of $\mu$ of the structure 3 . 
The structure 2 was solved by heavy-atom Patterson methods [39] and expanded using Fourier techniques. The non-hydrogen atoms were refined anisotropically. Hydrogen atoms were refined using the riding model. The final cycle of full-matrix least-squares refinement on $\mathrm{F}^{2}$ was based on 7926 observed reflections and 522 variable parameters and converged (largest parameter shift was 0.01 times its esd) with unweighted and weighted agreement factors of $R_{1}$ $=0.0520$ and $w \mathrm{R}_{2}=0.1500$, respectively (Table 2 ).

The structure $\mathbf{3}$ was solved by structure-invariant direct methods and expanded using Fourier techniques. Hydrogen atoms were refined using the riding model. The final cycle of full-matrix least-squares refinement on $\mathrm{F}^{2}$ was based on 35787 observed reflections and 1092 variable parameters and converged with unweighted and weighted agreement factors of: $R_{1}=0.0264$ and $w \mathbf{R}_{2}=0.0471$ (Table 2).

The structures 4 and 5 were solved by direct methods [40] and [41], respectively, and expanded using Fourier techniques. The non-hydrogen atoms were refined anisotropically. Hydrogen atoms were refined using the riding model. The final cycle of full-matrix least-squares refinement on $\mathrm{F}^{2}$ was based on 6300 observed reflections and 411 variable parameters and converged (largest parameter shift was 0.00 times its esd) with unweighted and weighted agreement factors of: $\mathrm{R}_{1}=0.0817$ and $w \mathrm{R}_{2}=0.2066$ for the structure $\mathbf{4}$, and on 13482 observed reflections and 856 variable parameters and converged (largest parameter shift was 0.00 times its esd) with unweighted and weighted agreement factors of: $\mathrm{R}_{1}=0.0673$ and $w \mathrm{R}_{2}=0.1993$ for the structure 5 (Table 2).

Neutral atom scattering factors were taken from International Tables for Crystallography (IT), [42]. Anomalous dispersion effects were included in $F_{\text {calc }}$ [43]; the values for $\Delta f^{\prime}$ and $\Delta f^{\prime \prime}$ were those of Creagh and McAuley [44]. The values for the mass attenuation coefficients are those of Creagh and Hubbell [45]. All calculations were performed using the CrystalStructure [46] crystallographic software package except for refinement, which was performed using SHELXL2013 [47] for the structure 2 and SHELXL Version 2014/7 [48] for the structures 3-

5. Table 2 contains selected crystallographic data and refinement details for the prepared compounds. 
Table 2 - Selected crystal data and structure refinement parameters for $\left[\mathrm{Nd}_{2}\left(\mathrm{NO}_{3}\right)_{6} \mathrm{~L}_{2}\right] \cdot\left(\mathrm{CH}_{3} \mathrm{CN}\right)_{3}(\mathbf{2}),\left[\mathrm{Nd}_{2}\left(\mathrm{NO}_{3}\right)_{4} \mathrm{~L}_{2}\right] \cdot\left[\mathrm{Nd}\left(\mathrm{NO}_{3}\right)_{5}\right] \cdot\left(\mathrm{CH}_{3} \mathrm{CN}\right)_{1.5}(\mathbf{3}), \mathrm{Ce}\left(\mathrm{NO}_{3}\right)_{3} \mathrm{~L}_{2}(\mathbf{4})$ and $\left[\mathrm{NdL}_{2}\right] \cdot\left(\mathrm{ClO}_{4}\right)_{3} \cdot \mathrm{C}_{2} \mathrm{H}_{5} \mathrm{OH}(\mathbf{5})$.

\begin{tabular}{|c|c|c|c|c|}
\hline Compound & 2 & 3 & 4 & 5 \\
\hline $\mathrm{CCDC}$ & 1541623 & 1541624 & 1541625 & 1555415 \\
\hline Empirical formula & $\mathrm{C}_{66} \mathrm{H}_{109} \mathrm{~N}_{17} \mathrm{Nd}_{2} \mathrm{O}_{26}$ & $\mathrm{C}_{63} \mathrm{H}_{104.5} \mathrm{~N}_{18.5} \mathrm{Nd}_{3} \mathrm{O}_{35}$ & $\mathrm{C}_{60} \mathrm{H}_{100} \mathrm{CeN}_{11} \mathrm{O}_{17}$ & $\mathrm{C}_{62} \mathrm{H}_{106} \mathrm{Cl}_{3} \mathrm{~N}_{8} \mathrm{NdO}_{21}$ \\
\hline Formula weight & 1845.17 & 2113.84 & 1387.63 & 1550.16 \\
\hline Temperature (K) & 93 & 173 & 93 & 93 \\
\hline Crystal system & monoclinic & triclinic & monoclinic & monoclinic \\
\hline Space group & $\mathrm{P} 2{ }_{1} / \mathrm{n}$ & $\mathrm{P} \overline{1}$ & $\mathrm{I} 2 / \mathrm{a}$ & $\mathrm{P} 2{ }_{1} / \mathrm{n}$ \\
\hline$a(\AA)$ & $11.990(2)$ & $12.2916(2)$ & $18.476(3)$ & $13.9932(16$ \\
\hline$b(\AA)$ & $15.170(3)$ & $17.7245(3)$ & $15.0303(18)$ & $36.161(4)$ \\
\hline$c(\AA)$ & $24.749(4)$ & 21.1897(3) & $26.418(3)$ & $14.9217(17$ \\
\hline$\alpha\left(^{\circ}\right)$ & 90 & $84.8998(14)$ & 90 & 90 \\
\hline$\beta\left(^{\circ}\right)$ & $101.613(3)$ & $89.0654(14)$ & $109.559(9)$ & $96.925(3)$ \\
\hline$\gamma\left({ }^{\circ}\right)$ & 90 & $70.5119(16)$ & 90 & 90 \\
\hline $\mathrm{V}\left(\AA^{3}\right)$ & $4409.4(13)$ & $4334.30(13)$ & $6913.0(16)$ & 7495.4(15) \\
\hline$Z$ & 2 & 2 & 4 & 4 \\
\hline $\begin{array}{l}\text { Density calc. } \\
\left(\mathrm{Mg} \cdot \mathrm{m}^{-3}\right)\end{array}$ & 1.390 & 1.620 & 1.333 & 1.374 \\
\hline$\mu\left(\mathrm{mm}^{-1}\right)$ & 1.24 & 1.86 & 0.73 & 0.87 \\
\hline Reflections collected & 35929 & 35787 & 34697 & 76194 \\
\hline $\begin{array}{l}\text { Independent } \\
\text { reflections }\end{array}$ & 7926 & 35787 & 6300 & 13482 \\
\hline $\mathrm{R}_{\text {int }}$ & 0.0564 & 0.0647 & 0.1095 & 0.0881 \\
\hline $\begin{array}{l}\text { Weighting scheme }{ }^{a} \\
(a, b)\end{array}$ & $0.0892,9.0001$ & $0.0177,0$ & $0.1247,75.4114$ & $0.1280,0$ \\
\hline Data in refinement & 7926 & 15374 & 6300 & 13482 \\
\hline Restraints, parameters & 21,522 & 46,1092 & 29,411 & 0,856 \\
\hline Goodness of fit on $\mathrm{F}^{2}$ & 1.06 & 0.71 & 1.07 & 1.06 \\
\hline $\begin{array}{l}\text { Residual electron } \\
\text { density }\left(\mathrm{e} \cdot \AA^{-3}\right)\end{array}$ & -1.21 to 1.41 & -0.89 to 1.79 & -1.42 to 3.40 & -1.71 to 1.70 \\
\hline $\mathrm{R}_{1}^{\mathrm{b}}\left(\mathrm{F}_{0}>2 \cdot \sigma\left(\mathrm{F}_{0}\right)\right)$ & $\begin{array}{c}0.0520 \\
\text { (6860 reflections) }\end{array}$ & $\begin{array}{c}0.0264 \\
\text { (15374 reflections) }\end{array}$ & $\begin{array}{c}0.0817 \\
\text { (5268 reflections) }\end{array}$ & $\begin{array}{c}0.0673 \\
\text { (10976 reflections) }\end{array}$ \\
\hline
\end{tabular}




\begin{tabular}{|l|c|l|l|l|}
\hline$w \mathrm{R}_{2}$ & 0.1459 & 0.0471 & 0.2066 & 0.1907 \\
\hline $\mathrm{R}_{1}{ }^{\mathrm{b}}$ (all data) & 0.0582 & 0.0668 & 0.0993 & 0.0790 \\
\hline$w \mathrm{R}_{2}$ (all data) & 0.1500 & 0.0482 & 0.2260 & 0.1993 \\
\hline${ }^{\mathrm{a}} \mathrm{W}=1 /\left[\sigma^{2}\left(\mathrm{~F}_{0}{ }^{2}\right)+(\mathrm{a} \cdot \mathrm{P})^{2}+\mathrm{b} \cdot \mathrm{P}\right]$, where $\mathrm{P}=\left(\mathrm{F}_{0}{ }^{2}+2 \cdot \mathrm{F}_{\mathrm{c}}{ }^{2}\right) / 3$ \\
\hline
\end{tabular}

\section{Electrospray Ionization - Mass Spectrometry.}

Ligand 1b was used in all electrospray ionization - mass spectrometry (ESI-MS) experiments. The samples with the 1:1 and 1:2 metal-to-ligand molar ratios were prepared by dissolution of the ligand and the respective metal salt $\operatorname{Pr}\left(\mathrm{NO}_{3}\right)_{3} \cdot 6 \mathrm{H}_{2} \mathrm{O}$ or $\mathrm{Nd}\left(\mathrm{NO}_{3}\right)_{3} \cdot 6 \mathrm{H}_{2} \mathrm{O}$ in acetonitrile $([\mathrm{Ln}(\mathrm{III})]=1 \mathrm{mg} / \mathrm{mL})$. Acetic acid was added to the samples $(0.1 \%$ vol. $)$ before the ESI-MS analysis. The ESI-MS spectrum of the ligand in acetonitrile ([L] $=2 \mathrm{mg} / \mathrm{mL} ; 0.1 \%$ vol. $\mathrm{CH}_{3} \mathrm{COOH}$ ) was recorded separately.

The ESI-MS measurements were conducted on a unit mass LC-MS instrument (Agilent 1260 HPLC and 6120 single quadrupole) equipped with an electrospray interface operated in positive ionization mode. The samples were analyzed by flow injection ESI-MS using the sample solvent as the carrier (flow rate $-0.2 \mathrm{~mL} / \mathrm{min}$; injection volume $-1 \mu \mathrm{L}$ ). Spectra were acquired over $\mathrm{m} / \mathrm{z}$ range of $300-2000$. High-resolution mass spectra were obtained by direct infusion of the sample, diluted to $10 \mu \mathrm{g} / \mathrm{mL}$ with acetonitrile, into the positive ESI ion source of the mass spectrometer (Agilent 6520) using a syringe pump (flow rate $-300 \mu \mathrm{L} /$ hour).

\section{Liquid-liquid extraction.}

Liquid-liquid extraction experiments and the data processing were performed by using the methods described previously [16]. The organic phase was pre-equilibrated with $3 \mathrm{M}$ solution of nitric acid. Inductively coupled plasma-mass spectrometry (ICP-MS) was used to measure the concentrations of the metal ions in aqueous solutions. All extraction tests were performed in triplicate. The reported D ratios are the mean of three experiments. 


\section{Conclusions}

Single-crystal XRD analysis was performed for the crystal structures of ortho-bismalonamide 1 (L) with trivalent lanthanides $\left[\mathrm{Nd}_{2}\left(\mathrm{NO}_{3}\right)_{6} \mathrm{~L}_{2}\right] \cdot\left(\mathrm{CH}_{3} \mathrm{CN}\right)_{3} \quad$ (2), $\left[\mathrm{Nd}_{2}\left(\mathrm{NO}_{3}\right)_{4} \mathrm{~L}_{2}\right] \cdot\left[\mathrm{Nd}\left(\mathrm{NO}_{3}\right)_{5}\right] \cdot\left(\mathrm{CH}_{3} \mathrm{CN}\right)_{1.5}(\mathbf{3}), \mathrm{Ce}\left(\mathrm{NO}_{3}\right)_{3} \mathrm{~L}_{2}(\mathbf{4})$ and $\left[\mathrm{NdL}_{2}\right] \cdot\left(\mathrm{ClO}_{4}\right)_{3} \cdot \mathrm{C}_{2} \mathrm{H}_{5} \mathrm{OH}(\mathbf{5})$. The coordination environment of the metal ions in these complexes was established. It was demonstrated that ortho-bismalonamides can act as either bidentate or tetradentate ligands in their complexes with lanthanides(III). The crystallography data is reconciled with the results of the electrospray ionization - mass spectrometry (ESI-MS) investigations of the solution-state complexes of the bismalonamides with trivalent lanthanides. The unusual form of the ligand coordination to a metal ion into dimers was discovered in the nitrato complexes of orthobismalonamide 1b with lanthanides both in solids and solutions. The results of single-crystal XRD and ESI-MS studies suggest that the advantageous liquid-liquid extraction of trivalent lanthanides with ortho-bismalonamides is likely favored by the entropy effect of a polydentate ligand. 


\section{Supplementary data}

CCDC 1541623, 1541624, 1541625 and 1555415 contain the supplementary crystallographic data for the structures $\mathbf{2}, \mathbf{4}, \mathbf{5}$, and $\mathbf{3}$, respectively. These data can be obtained free of charge via http://www.ccdc.cam.ac.uk/conts/retrieving.html, or from the Cambridge Crystallographic Data Centre, 12 Union Road, Cambridge CB2 1EZ, UK; fax: (+44) 1223-336-033; or e-mail: deposit@ccdc.cam.ac.uk.

\section{Acknowledgements}

The research leading to these results has received funding from the European Community's Seventh Framework Programme ([FP7/2007-2013]) under grant agreement no. 607411 (MCITN EREAN: European Rare Earth Magnet Recycling Network). This publication reflects only the authors' views, exempting the Community from any liability. Project website: http://www.erean.eu. 


\section{References}

1. Binnemans, K., et al., Recycling of rare earths: a critical review. Journal of Cleaner Production, 2013. 51: p. 1-22.

2. Yang, Y., et al., REE recovery from end-of-life NdFeB permanent magnet scrap: a critical review. Journal of Sustainable Metallurgy, 2016: p. 1-28.

3. Musikas, C., Completely incinerable extractants for the nuclear industry - a review. Mineral Processing and Extractive Metallurgy Review, 1997. 17(1-4): p. 109-142.

4. Cuillerdier, C., C. Musikas, and L. Nigond, Diamides as actinide extractants for various waste treatments. Separation Science and Technology, 1993. 28(1-3): p. 155-175.

5. Thiollet, G. and C. Musikas, Synthesis and uses of the amides extractants. Liquid-liquid extraction and Ion Exchange, 1989. 7(5): p. 813-827.

6. Tian, Q. and M.A. Hughes, The mechanism of extraction of $\mathrm{HNO}_{3}$ and neodymium with diamides. Hydrometallurgy, 1994. 36(3): p. 315-330.

7. Spjuth, L., et al., Extraction of actinides and lanthanides from nitric acid solution by malonamides. Radiochimica Acta, 1997. 78(s1): p. 39-46.

8. Dul, M.-C., et al., Synthesis of fluorinated malonamides and use in L/L extraction of felements. Tetrahedron Letters, 2013. 54(46): p. 6271-6274.

9. Nigond, L., et al., Recent advances in the treatment of nuclear wastes by the use of diamide and picolinamide extractants. Separation Science and Technology, 1995. 30(79): p. 2075-2099.

10. Sasaki, Y. and S. Tachimori, Extraction of actinides(III), (IV), (V), (VI), and lanthanides(III) by structurally tailored diamides Liquid-liquid extraction and Ion Exchange, 2002. 20(1): p. 21-34.

11. Persson, I., et al., Hydration of lanthanoid(III) ions in aqueous solution and crystalline hydrates studied by EXAFS spectroscopy and crystallography: the myth of the "gadolinium break". Chemistry - A European Journal, 2008. 14(10): p. 3056-3066.

12. Dam, H.H., D.N. Reinhoudt, and W. Verboom, Multicoordinate ligands for actinide/lanthanide separations. Chemical Society Reviews, 2007. 36(2): p. 367-377.

13. Murillo, M.T., et al., Bismalonamides (BISMA) as new extractants for Am (III) and Eu (III) from aqueous high-level wastes. Radiochimica Acta, 2008. 96(4-5/2008): p. 241257.

14. Janczewski, D., et al., Tripodal (N-alkylated) $C M P(O)$ and malonamide ligands: synthesis, extraction of metal ions, and potentiometric studies. New Journal of Chemistry, 2007. 31(1): p. 109-120. 
15. Dam, H.H., D.N. Reinhoudt, and W. Verboom, Influence of the platform in multicoordinate ligands for actinide partitioning. New Journal of Chemistry, 2007. 31(9): p. 1620-1632.

16. Tyumentsev, M.S., et al., The liquid-liquid extraction of rare earth elements from nitrate media with novel polyamides containing malonamide groups. Hydrometallurgy, 2016. 164: p. 24-30.

17. Lumetta, G.J., et al., Neodymium(III) complexes of dialkylphosphoric and dialkylphosphonic acids relevant to liquid-liquid extraction systems. Inorganic Chemistry, 2016. 55(4): p. 1633-1641.

18. Parks, B.W., et al., Solution and structural investigations of ligand preorganization in trivalent lanthanide complexes of bicyclic malonamides. Inorganic Chemistry, 2006. 45(4): p. 1498-1507.

19. Byers, P., et al., The structure of the complex formed by tetraethylmalondiamide and lanthanum(III) nitrate. Polyhedron, 1994. 13(3): p. 349-352.

20. Cui, Y.U., et al., Preparation, characterization and crystal structure of the complex formed between $N, N, N^{\prime}, N^{\prime}$-tetrabutylmalonamide and lanthanum(III)nitrate. Journal of the Serbian Chemical Society, 2006. 71(5): p. 513-519.

21. Den Auwer, C., et al., Crystallographic, X-ray absorption, and IR studies of solid-and solution-state structures of tris(nitrato) $N, N, N^{\prime}, N^{\prime}$-tetraethylmalonamide complexes of lanthanides. Comparison with the americium complex. Inorganic Chemistry, 2000. 39(7): p. 1487-1495.

22. Chan, G.Y.S., et al., Liquid-liquid extraction of metal ions from nitric acid solution using $N, N^{\prime}$-substituted malonamides. Experimental and crystallographic evidence for two mechanisms of extraction, metal complexation and ion-pair formation. Journal of the Chemical Society, Dalton Transactions, 1997(4): p. 649-660.

23. B. Iveson, P., et al., Structural studies of lanthanide complexes with new hydrophobic malonamide liquid-liquid extraction agents Journal of the Chemical Society, Dalton Transactions, 1999(20): p. 3605-3610.

24. Rapko, B.M., et al., Coordination of lanthanide nitrates with $N, N, N^{\prime}, N^{\prime}$ tetramethylsuccinamide. Inorganic Chemistry, 1999. 38(20): p. 4585-4592.

25. Drew, M.G.B., et al., Unusual complexes formed by the early lanthanides with 2,6bis(5,6-dialkyl-1,2,4-triazin-3-yl)-pyridines. Inorganic Chemistry Communications, 2001. 4(9): p. 462-466.

26. Shannon, R., Revised effective ionic radii and systematic studies of interatomic distances in halides and chalcogenides. Acta Crystallographica Section A, 1976. 32(5): p. 751-767.

27. Castellano, E. and R. Becker, Structural studies of addition-compounds of lanthanides with organic-ligands. 1. Structures of samarium and erbium hexafluorophosphates with 
$N, N, N^{\prime}, N^{\prime}$-tetramethylmalonamide. Acta Crystallographica Section B - Structural Science, 1981. 37: p. 61-67.

28. Fedosseev, A.M., et al., Synthesis, crystal structure and some properties of new perrhenate and pertechnetate complexes of $\mathrm{Nd}^{3+}$ and $\mathrm{Am}^{3+}$ with 2,6bis(tetramethylfurano)-1,2,4-triazin-3-yl)-pyridine, tris(2-pyridylmethyl)amine and N,N'-tetraethylmalonamide. Polyhedron, 2008. 27(8): p. 2007-2014.

29. Antonio, M.R., et al., Aggregation in liquid-liquid extraction systems containing a malonamide, a dialkylphosphoric acid and their mixtures. Separation Science and Technology, 2008. 43(9-10): p. 2572-2605.

30. Leclerc, E., et al., Mass spectrometry and theoretical investigation of dialkylphosphoric acid-lanthanide complexes. Radiochimica Acta, 2008. 96: p. 85-92.

31. Crowe, M.C., et al., Investigating Bidentate and Tridentate Carbamoylmethylphosphine Oxide Ligand Interactions with Rare-Earth Elements Using Electrospray Ionization Quadrupole Ion Trap Mass Spectrometry. Inorganic Chemistry, 2005. 44(18): p. 64156424.

32. Table of nuclides. Nuclear Data Center at KAERI (Korea Atomic Enery Research Institute). http://atom.kaeri.re.kr.

33. Ellis, R.J., et al., Periodic behavior of lanthanide coordination within reverse micelles. Chemistry - A European Journal, 2013. 19(8): p. 2663-2675.

34. Ellis, R.J., et al., Complexation-induced supramolecular assembly drives metal-ion extraction. Chemistry - A European Journal, 2014. 20(40): p. 12796-12807.

35. Antonio, M.R., et al., Structural insights into the multinuclear speciation of tetravalent cerium in the tri-n-butyl phosphate-n-dodecane solvent extraction system. Physical Chemistry Chemical Physics, 2017.

36. Furr, A.K., CRC Handbook of Laboratory Safety, 5th Edition. 2000: CRC Press.

37. CrystalClear: Data Collection and Processing Software, Rigaku Corporation (19982015). Tokyo 196-8666, Japan.

38. CrysAlis PRO. version 1.171.38.43i: Data Collection and Processing Software, Rigaku Oxford Diffraction. Rigaku Corporation (2015). Tokyo, Japan.

39. PATTY: Beurskens, P.T., Admiraal, G., Behm, H., Beurskens, G., Smits, J.M.M. and Smykalla, C. (1991). Z. f. Kristallogr. Suppl. 4, p. 99.

40. SIR2011: Burla, M. C., Caliandro, R., Camalli, M., Carrozzini, B., Cascarano, G. L., Giacovazzo, C., Mallamo, M., Mazzone, A., Polidori, G. and Spagna, R. (2012). J. Appl. Cryst. 45, p. 357-361.

41. SIR2004: Burla, M. C., Caliandro, R., Camalli, M., Carrozzini, B., Cascarano, G. L., De Caro, L., Giacovazzo, C., Polidori, G. and Spagna R. (2005). J. Appl. Cryst. 38, p. 381-388. 
42. International Tables for Crystallography, Vol. C (1992). Ed. A.J.C. Wilson, Kluwer Academic Publishers, Dordrecht, Netherlands, Table 6.1.1.4, p. 572.

43. Ibers, J. A. and Hamilton, W. C.; Acta Crystallogr., 17, 781 (1964).

44. Creagh, D. C. and McAuley, W.J .; "International Tables for Crystallography", Vol. C, (A.J.C. Wilson, ed.), Kluwer Academic Publishers, Boston, Table S1.2.6.8, pp. 219-222 (1992).

45. Creagh, D. C. and Hubbell, J.H..; "International Tables for Crystallography", Vol. C, (A.J.C. Wilson, ed.), Kluwer Academic Publishers, Boston, Table S1.2.4.3, pp. 200-206 (1992).

46. CrystalStructure 4.2: Crystal Structure Analysis Package, Rigaku Corporation (20002015). Tokyo 196-8666, Japan.

47. SHELXL2013: Sheldrick, G. M. (2008). Acta Cryst. A64, p. 112-122.

48. SHELXL Version 2014/7: Sheldrick, G. M. (2008). Acta Cryst. A64, p. 112-122.

\section{Table of Contents}

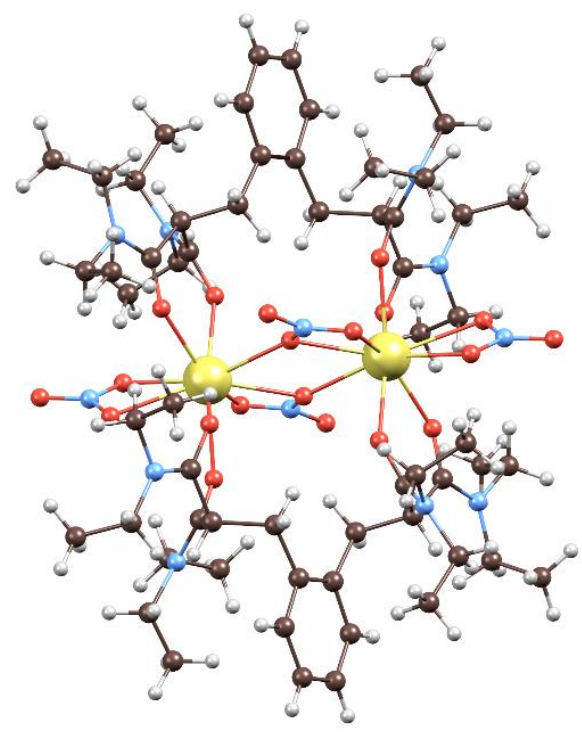

The dimeric cation $\left[\mathrm{Nd}_{2}\left(\mathrm{NO}_{3}\right)_{4} \mathrm{~L}_{2}\right]^{2+}$ of the structure $\left[\mathrm{Nd}_{2}\left(\mathrm{NO}_{3}\right)_{4} \mathrm{~L}_{2}\right] \cdot\left[\mathrm{Nd}\left(\mathrm{NO}_{3}\right)_{5}\right] \cdot\left(\mathrm{CH}_{3} \mathrm{CN}\right)_{1.5}$ is presented in the figure (the color code: $\mathrm{Nd}$ - yellow, $\mathrm{O}$ - red, $\mathrm{N}-$ blue, $\mathrm{C}$ - gray, $\mathrm{H}$ - white), where L stands for 2,2'-(1,2-phenylenebis(methylene))bis( $N, N, N^{\prime}, N^{\prime}$-tetraethylmalonamide). Such coordination mode is new for the complexes of multicoordinate ligands with trivalent lanthanides.

Key words: dimeric complex of neodymium with bismalonamide 